\title{
Can glyphosate's disruption of the gut microbiome and induction of sulfate deficiency explain the epidemic in gout and associated diseases in the industrialized world?
}

\author{
Stephanie Seneff,, ${ }^{1, *}$ Nicholas J. Causton, ${ }^{2}$ Gregory L. Nigh, ${ }^{3}$ Gerald Koenig ${ }^{4,5}$ and Dette Avalon ${ }^{6}$ \\ ${ }^{1}$ Computer Science and Artificial Intelligence Laboratory, MIT, Cambridge, Mass. 02139, USA \\ ${ }^{2}$ Independent Researcher, UK \\ ${ }^{3}$ Naturopathic Oncology, Immersion Health, Portland, Oregon 97214, USA \\ ${ }^{4}$ Health-e-Iron, LLC, 2800 Waymaker Way, No. 12, Austin, Texas 78746, USA \\ ${ }^{5}$ Iron Disorders Institute, Greenville, South Carolina 29615, USA \\ ${ }^{6}$ Avalon Health \& Wellness, 3524 East 15th Ave, Anchorage, Alaska 99508, USA
}

\begin{abstract}
Gout is an acute or chronic inflammatory disease characterized by intense pain, redness and swelling in joints, mainly the metatarsophalangeal joint. Gout is linked to an increased risk of diabetes and heart disease. The traditional medical view holds that high dietary purines, fructose and alcohol are key causal factors. However, this does not explain the entirety of the pathophysiology. In this paper, we review the literature on gout and propose a functional rôle for the inflammatory signaling cascade to restore vascular health. Our findings suggest that the primary factor behind the recent gout epidemic is dietary glyphosate, with iron overload and fungus overgrowth as secondary contributing factors. The increase in gout prevalence in the United Kingdom correlates well with both diabetes prevalence and the use of glyphosate in agriculture. The activities that take place in the gouty joint are directed towards renewing sulfate supplies to the immune cells and to the vasculature. Dangerously high serum viscosity impairs vascular sulfate synthesis, promoting crystal formation and immune cell infiltration into the joint, provoking a gout attack. The resulting complex signaling cascade leads to hydrogen sulfide $\left(\mathrm{H}_{2} \mathrm{~S}\right)$ synthesis, release of ATP and reactive oxygen, and activation of enzymes that oxidize $\mathrm{H}_{2} \mathrm{~S}$ to sulfate, eventually restoring sulfate supplies to the macrophages invading the synovial fluid. We urge that government regulators reassess the toxicity of glyphosate to humans.
\end{abstract}

Keywords: glyphosate, gout, fungus infection, serum viscosity, sulfate, urate

\section{INTRODUCTION}

Gout is an ancient disease, which has been known at least since Babylonian times. The word "gout" is derived from the Latin word "gutta" (drop); it signifies the belief that a poison, seeping into the joint drop by drop, is the cause [1]. Much is understood about the aetiology of gout, although there are also still many mysteries yet to be resolved. Gout is an inflammatory joint disease that is typically episodic and localized to certain joints, especially the metatarsophalangeal (MTP) ${ }^{1}$ joint and other joints in feet and fingers. An acute episode of gout is usually triggered by urate crystals in the joint, which induce a cascade reaction beginning with the influx of immune cells, especially neutrophils, which release cytokines such as IL- $1 \beta$ and IL-6, causing an inflammatory response leading to oxidative damage and intense pain, and terminating when feedback responses finally dampen the signal.

While gout is associated with high serum urate, the association is not as strong as would be expected. Many people with elevated serum urate never experience gout, and many gout sufferers have normal levels of serum urate [2]. Thus, it is generally agreed that something else

\footnotetext{
*Corresponding author. E-mail: seneff@csail.mit.edu

${ }^{1}$ List of Abbreviations: ABC: ATP-binding cassette; ALA: $\delta$-aminolevulinic Acid; ALS: amyotrophic lateral sclerosis; BMI: body mass index; BNF: British National Formulary; CDC: Centers for Disease Control and Prevention; CK: creatine kinase; CRD: Chemicals Regulation Division; CSE: cystathionine- $\gamma$-Lyase; DEFRA: Department for Environment, Food \& Rural Affairs; eNOS: endothelial nitric oxide synthase; EVSP: electrokinetic vascular streaming potential; FAO: Food and Agriculture Organization; GGT: gamma glutamyl transpeptidase; HDAC: histone deacetylase; HSCIC: Health and Social Care Information Centre; IARC: International Agency for Research on Cancer; IBD: inflammatory bowel disease; LDL: low density lipoprotein; MTP: metatarsophalangeal; MiG: microbial index of gout; NAFLD: nonalcoholic fatty liver disease; NSAIDS: nonsteroidal antiinflammatory drugs; PAPS: 3'-phosphoadenosine-5'-phosphosulfate; PCA: prescription cost analysis; PCr: phosphocreatine; PON1: paraoxonase type 1; PPA: Prescription Pricing Authority; PUS Stats: Pesticide USage Statistics; (UK NHS); QOF: Quality and Outcomes Framework; ROS: reactive oxygen species; SB: sodium butyrate; sGAGs: sulfated glycosaminoglycans; SO: sulfite oxidase; TLR4: toll-like receptor 4.
} 
works synergistically with urate to induce crystal formation. Immunoglobulins, especially IgG, have been linked to gout, and autoimmune reactions to damaged cartilage have been shown to induce collagen-specific IgGs that bind to the cartilage, and likely attract urate due to their positive charge. It has only been very recently that imaging techniques have been able to capture urate crystals in situ, and these have revealed that urate crystals can coat a section of cartilage and remain there through intervening periods between acute episodes of gout [3].

Gout and, more generally, hyperuricaemia are associated with multiple other diseases and conditions that are prevalent today, including hypertension, metabolic syndrome, coronary artery disease, cerebrovascular disease, vascular dementia, preeclampsia, stroke, deep vein thrombosis and kidney disease [4-12]. Triggers of acute gout episodes include dietary fructose, dietary meats rich in purines, alcohol and elevated levels of serum triglycerides, and some of these triggers are also linked to those other diseases. Both fructose and alcohol can be explained by their ability to increase serum urate production in the liver, and purines are direct precursors of urate. The rôle of triglycerides is less well understood.

The prevalence of gout and of most of the other diseases has been increasing at an alarming rate in recent times, especially in the industrialized world [13, 14]. The prevalence of gout in the USA today is about $3.9 \%$, with the prevalence of hyperuricaemia now estimated to be over 21\% [15]. A study based in New England published in 1972 gave a prevalence of gout of only $0.37 \%$, revealing a tenfold increase during the intervening years [16].

In the United Kingdom, the prevalence of gout was $2.5 \%$ of the general population in 2012, an increase of $64 \%$ since 1997 [17]. A study from 2016 on gout in South Australia found that $5.2 \%$ of the population had gout $(8.5 \%$ of males and $2.1 \%$ of females), while hyperuricaemia occurred in $16.6 \%$ of the population [18]. Gout was associated with high body mass index (BMI) and with renal disease. Gout prevalence has also been increasing in New Zealand [19]. Gout had been extremely rare in China, but the number of confirmed cases had reached 75 million by the end of 2010 [20].

Although urate is the source of the crystals that precipitate a gout attack, urate is generally viewed as beneficial due to its ability to act as an endogenous antioxidant [21]. Urate is a chain-breaking antioxidant that contributes nearly two thirds of the free radical scavenging action in the blood, protecting DNA and erythrocytes from oxidative damage [21]. Low serum urate levels are a risk factor for amyotrophic lateral sclerosis (ALS), likely due to insufficient protection from oxidative damage in muscle cells [22]. In fact, it has been argued that human evolution has led to favouring urate over ascorbate as a major serum antioxidant, as evidenced by the loss of the gene for uricase, the enzyme that metabolizes urate, and the concurrent loss of L-glucuronate oxidase, the enzyme that synthesizes vitamin C [23].

An acute episode of gout spontaneously resolves usually within a week, even in the absence of treatment $[24,25]$. However, repeated episodes can lead to joint destruction. The process leading to resolution is poorly understood, although it appears that clearance of the crystals by phagocytes, dissolution of the crystals, the induction of anti-inflammatory factors, and alterations in the crystal surface by coating with serum factors are involved [26-30].

In the case of an inflammatory response to pathogens, it is easy to justify that the resulting reactive oxygen species (ROS) serve a purpose in keeping the pathogens in check. Gout, however, is an aseptic inflammatory response, hence it becomes much less clear what rôle the damaging ROS play. In this paper, we develop the idea that the ROS produced in an inflammatory cascade are used to oxidize hydrogen sulfide to sulfate, thus renewing sulfate supplies both locally and systemically.

It has only been in recent years that an important rôle for hydrogen sulfide $\left(\mathrm{H}_{2} \mathrm{~S}\right)$ has been recognized in joint diseases, although the mechanisms remain poorly understood. $\mathrm{H}_{2} \mathrm{~S}$ levels are elevated in the arthritic joint compared both to blood serum in the same patient and to joint $\mathrm{H}_{2} \mathrm{~S}$ levels in controls [31]. The inflammasome cascade induces in chondrocytes the expression of cystathionine- $\gamma$-lyase (CSE), an enzyme that metabolizes cysteine to release $\mathrm{H}_{2} \mathrm{~S}$. Low-dose $\mathrm{H}_{2} \mathrm{~S}$ release by drugs such as GYY4137 has been shown to inhibit the inflammatory response [32]. It is noteworthy that specially designed nonsteroidal anti-inflammatory drugs (NSAIDS) that release $\mathrm{H}_{2} \mathrm{~S}$ have been found to be superior to traditional NSAIDS in controlling inflammation, with reduced risk of gastrointestinal ulceration and bleeding [33].

High serum viscosity may be the most important trigger for a gout attack. The relationship between various measures of blood viscosity and cardiovascular events is at least as strong as the relationship between these events and serum low-density lipoprotein (LDL) or blood pressure [34]. The most important factor in viscosity is the haematocrit; a high haematocrit is linked to hyperuricaemia [35]. High serum triglycerides [36], high serum glucose [37] and a high ratio of serum LDL to HDL [38] are also contributors to elevated serum viscosity, and diabetes and hyperlipidaemia co-occur with 
gout. A little known fact is that the activity of sulfite oxidase, which oxidizes sulfite to sulfate, is inhibited by high viscosity of the medium $[39,40]$. It is possible that a gout event following a heavy meal is precipitated by a dangerously high (critical) blood viscosity, which interferes with sulfate synthesis in the vasculature.

Here, we present government-provided data from the United Kingdom on pharmaceutical prescription drugs that treat gout in order to establish an estimate of the rate of increase over time. We also show temporal trends of glyphosate usage on all crops in the UK and of the rates of diabetes over time in the UK, and show that all of these exhibit similar trends.

Subsequently, we review the research literature on gout, and we show how chronic dietary exposure to the pervasive herbicide glyphosate may be a crucial factor in the epidemic of gout in the industrialized world. An equally important goal of the paper is to explain the aetiology of gout, with the novel view that the inflammatory response in the gouty joint achieves a larger goal of rescuing the vasculature from acute sulfate deficiency, induced by chronic low-dose exposure to glyphosate.

\section{METHODS}

In this section, we briefly describe the online sources of UK government data made available for prescription drugs for gout, cumulative glyphosate usage on all crops, and diabetes prevalence in the UK, as well as diabetes incidence in the USA, and the methods we used to analyse them.

\subsection{Gout prescription data}

Prescription statistics data were extracted predominantly from yearly Prescription Cost Analysis (PCA) reports for England produced by the UK Department of Health. We used the following British National Formulary (BNF) classification to define specific drugs to track over time:

10.1 Drugs used in rheumatic diseases and gout 10.1.4 Gout and cytotoxic-induced hyperuricaemia.

\subsection{Glyphosate usage data}

Pesticide usage data were extracted from survey data produced by Pesticide USage Statistics (PUS Stats²), a division of the UK Department for Environment, Food \& Rural Affairs (DEFRA).

Within these pesticide usage statistics there are 24 crop groups, 413 active substance classifications and 29 Food and Agriculture Organization (FAO) chemical type categories. We examined them to search for correlation with the (expected) rate of increase in gout. We used data for the "all crops" category in Great Britain.

\subsection{Diabetes data}

Prevalence data are available from the NHS Quality and Outcomes Framework (QOF) online database ${ }^{3}$ for the years 2004-2015. There are also single data points for 1996 and 1970. Intervening years were linearly interpolated.

\subsection{Data sources}

Prescription statistics: All prescription statistics data were obtained from the UK Department of Health (DH). Data were sourced at differing times and from various subdivisions of the $\mathrm{DH}$, as described below:

2004 to 2015: Extracted from yearly Prescription Cost Analysis (PCA) reports, supplied in 2016 by the Health and Social Care Information Centre (HSCIC), a division of $\mathrm{DH}$.

1980 to 2004: Supplied in 2005 by MB Prescription Statistics, a division of DH.

Data within this range were dealt with according to two different methods:

1991 to 2004: From the Prescription Cost Analysis (PCA) system supplied by the Prescription Pricing Authority (PPA), based on a full analysis of all prescriptions dispensed in the community.

1980-1990: Based on a 1-in-200 sample and excluding dispensing doctors.

\subsection{Pesticide usage statistics}

The programme of pesticide usage surveys (PUS Stats ${ }^{2}$ ) is commissioned by the independent Expert Committee on Pesticides and funded by the Chemicals Regulation Directorate. Data are collected by the Pesticide Usage Survey Teams at Fera Science Ltd, the Scottish Agricultural Science Agency and the Agri-Food and Biosciences Institute of Northern Ireland.

Fera is commissioned to conduct agricultural, horticultural and amenity pesticide usage surveys by the Chemicals Regulation Division (CRD) of the Health and Safety Executive. The surveys are funded from the pesticides charge on turnover scheme.

\subsection{Diabetes prevalence}

Data were sourced from the NHS Quality and Outcomes Framework (QOF) for the people (age $>17$ ) diagnosed with diabetes for the years 2004-2015. Also, single data

\footnotetext{
${ }^{2}$ https://secure.fera.defra.gov.uk/pusstats/

${ }^{3}$ content.digital.nhs.uk/qof-online
} 
points for 1996 and 1970 were available with intervening years predicted by linear interpolation. Data was supplied by Diabetes UK:

2004 to 2015: Originated from the NHS QOF, which is the annual reward and incentive programme detailing general practice achievement results.

1996: Estimate from British Diabetic Association.

1970: Estimate from Diabetes UK's Balance magazine.

For diabetes incidence in the USA, data were obtained from the Centers for Disease Control and Prevention (CDC): number (in millions) of civilian, noninstitutionalized persons with diagnosed diabetes, USA, 1980-2014.

\section{RESULTS}

Examination of prescription data revealed a nearly tenfold (978\%) increase in gout prescriptions between 1980 and 2015, with Allopurinol accounting for over $90 \%$ of gout-related prescriptions. Other drugs include Colchicine, Febuxostat, Probenecid, Sulfinpyrazone and Benzbromarone.

The plots for cumulative glyphosate usage and gout prescriptions are superimposed in Figure 1. A pre-glyphosate baseline level of prescriptions was established at 220,000 by correlation with diabetes prevalence, regression analysis and an available data point for diabetes in 1970 .
Pre-1990 glyphosate accumulation was calculated using linear regression back to a start point of 1974.

Examination of pesticide usage data revealed strong correlation between cumulative weight of glyphosate applied in the "all crops" category (GB) and incidence of gout. No other pesticide nor combination of categories and classifications showed such strong correlation.

Due to known similarities in the biochemical mechanisms between gout and diabetes, we examined this possible correlation, and the results are shown in Figs 2 and 3. Fig. 2 shows gout prescriptions compared to the number of patients with diabetes in the UK. The two curves correspond remarkably well, and this supports the idea that the two diseases share an underlying aetiology, which may be related to glyphosate toxicity.

We also compared diabetes levels in the UK to those in the USA, as shown in Fig. 3. Diabetes has been seen to be strongly correlated with glyphosate usage on core crops in the United States in previous work [41] (more generally, a strong correlation is seen between the emergence of the diabetes epidemic in the USA and the increased production of all synthetic chemicals [42]).

Finally, Fig. 4 shows the time trends for diabetes in the UK superimposed on the trends in the use of glyphosate on all crops in the UK. The strong correspondence of these two curves is consistent with the trends noted by Swanson et al. [41] in the USA relating glyphosate to diabetes.
$6 \quad$ Gout Prescriptions (England) vs Glyphosate usage (GB)



Figure 1. Prescriptions of pharmaceutical drugs used to treat gout in England (orange) (colour online) and cumulative glyphosate usage on all crops in Great Britain (blue). Data sources are given in the text. 


\section{Gout (England) vs Diabetes (UK)}

7

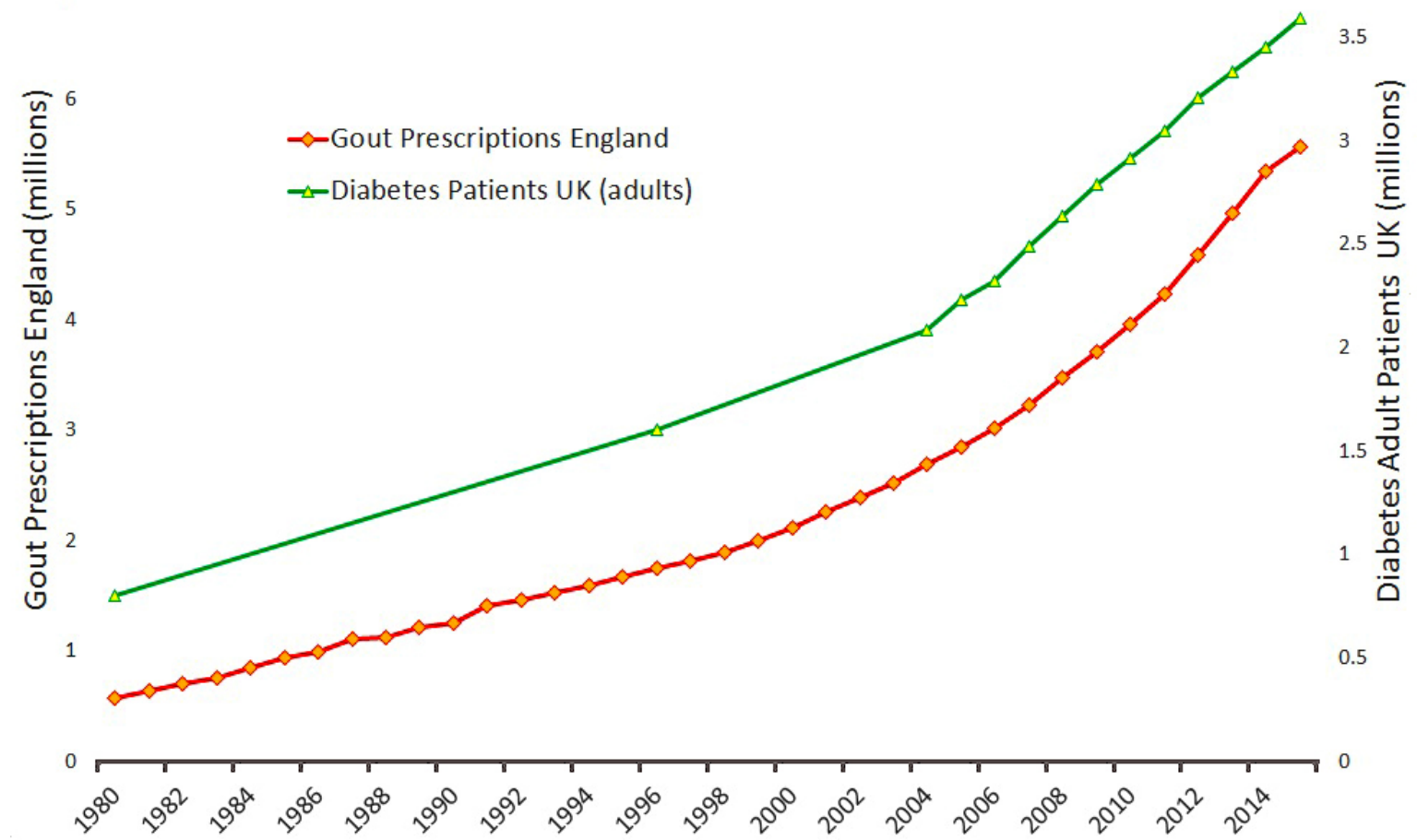

Figure 2. Prescriptions of pharmaceutical drugs used to treat gout in England (orange) (colour online) and number of adults with diagnosis of diabetes (green) in the entire UK. Data sources are given in the text.

\section{Diabetes - UK vs US}
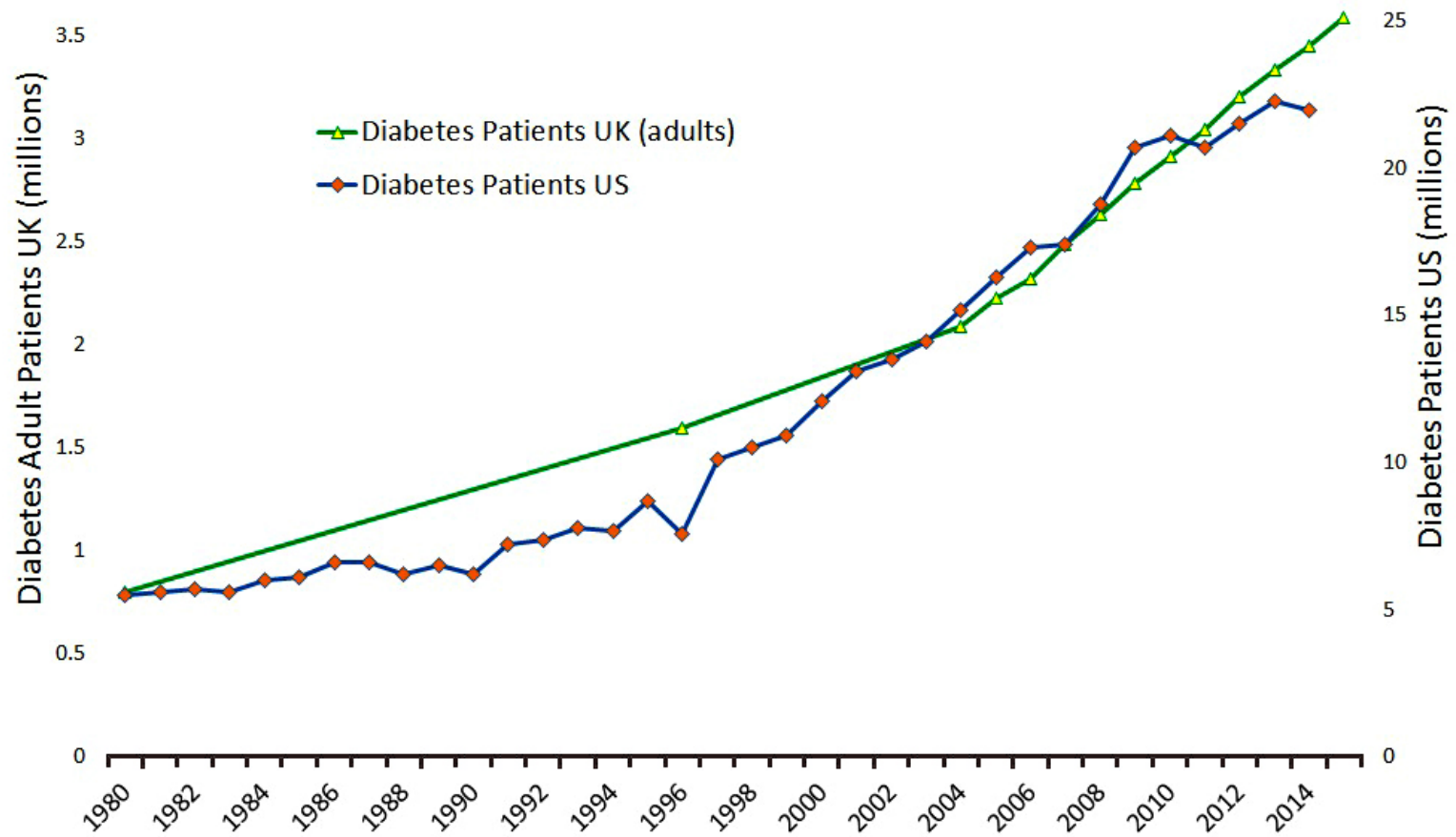

Figure 3. Diabetes trends in the UK (green) (colour online) and the USA (blue). Data sources are given in the text. 
50

45 Glyphosate usage (GB) vs Diabetes (UK)

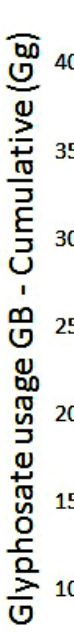

5
4.5

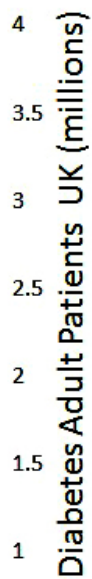

0.5

0

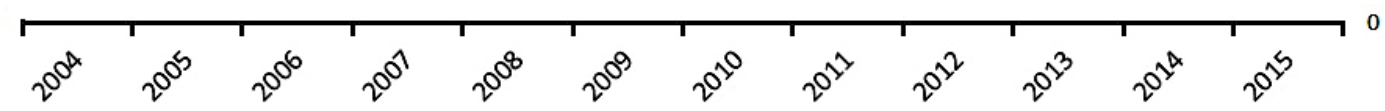

Figure 4. Diabetes trends in the UK (green) (colour online) with glyphosate usage on core crops (blue). Data sources are given in the text.

\section{DISCUSSION}

\subsection{Glyphosate usage and human diseases: Probable causal mechanism}

Core crops genetically engineered to resist glyphosate, introduced in the USA in the late 1990s and then widely adopted, have led to over-reliance on glyphosate as a herbicide [43]. Glyphosate usage in the USA increased dramatically in the decade following the introduction of glyphosate-resistant crops, and today accounts for 56\% of global glyphosate use. No other pesticide has enjoyed such intensive and widespread use. Yet, farmers had not anticipated the emergence of glyphosate-resistant weeds invading the resistant crops, necessitating ever-higher usage rates.

Government regulators have mostly been lax about regulating or even monitoring glyphosate usage, mostly because we have been led to believe by its first manufacturer that it is practically harmless to humans. However, much recent research reveals that it is not. The World Health Organization's International Agency for Research on Cancer (IARC) declared glyphosate a probable carcinogen in 2015, based on a review of evidence [44]. A 2014 study by Swanson et al. compared glyphosate usage on core crops in the USA with the rise in prevalence of multiple debilitating diseases [41]. They found striking correlations with a long list of diseases, including diabetes, inflammatory bowel disease, autism, dementia, kidney disease, pancreatic cancer and intestinal infection. A recent study analysing liver enzymes in rats exposed to low doses of the formulation Roundup over their lifespan identified several enzymes that were disrupted [45]. Another study has discovered that glyphosate suppresses the release of thyroid-stimulating hormone from the pituitary gland, leading to hypothyroidism in the offspring of an exposed pregnant dam [46]. An earlier paper had proposed such a mechanism and predicted that it would be causal for autism [47].

Three recent reviews of glyphosate have centred on the idea that glyphosate, acting as an amino acid analogue of glycine, may become incorporated into proteins in place of glycine through a coding error during protein synthesis [48-50]. The first study by Samsel and Seneff showed how disruption of multiple proteins in the body with highly conserved glycines could easily explain the correlations seen in the Swanson et al. paper [48]. The study by Seneff et al. [49] focused specifically on ALS, and showed that a large number of proteins implicated in ALS have multiple glycine dependencies. The follow-on study by Samsel and Seneff [50] linked glyphosate to multiple autoimmune diseases via molecular mimicry due to resistance to proteolysis of glyphosate-contaminated foreign proteins.

Glyphosate has recently been shown to be taken up by nasal and gastrointestinal mucosal cells via active 
transport across L-type amino acid channels, LAT1/ LAT2 [51]. This finding is not altogether unexpected, since glyphosate is an amino acid. LAT1 mRNA is highly expressed in the human foetal liver, bone marrow, placenta, testis and brain, as well as in tumour cells [52]. In general, any cell type with a high proliferation rate will need to take up substantial amounts of amino acids for growth, and this puts such a cell at higher risk of glyphosate accumulation. This may explain why Monsanto's early research on radiolabeled glyphosate found the highest accumulation levels in bone marrow $[53,54]$. What this also implies is that any tissue suffering from metabolic stress and/or injury, necessitating the infiltration of immune cells derived from precursor cells stored in the bone marrow, can expect to receive an unintended supply of glyphosate brought in as "stealth cargo" by the infiltrating immune cells. Glyphosate has been shown to disrupt the balance of gut microbes, favouring an overgrowth of pathogens, and this leads to an inflammatory response, such as inflammatory bowel disease (IBD) [55]. The infiltrating immune cells expose the abdominal adipocytes to glyphosate, disrupting their ability to release fats, and therefore promoting abdominal fat accumulation. Similarly, an inflammatory response in the gouty joint, initially triggered by urate crystals, will induce the infiltration of neutrophils derived from glyphosatecontaminated bone marrow, increasing the concentration of glyphosate in the joint and enhancing the disease process.

Susceptibility to trauma may be a factor in the localization of gout in the big toe. Trauma indirectly enhances crystal nucleation by lowering synovial $\mathrm{pH}$ [56]. The tendency of uric acid to nucleate increases rapidly as $\mathrm{pH}$ decreases [57]. Glyphosate may play a synergistic rôle through its ability to induce subclinical metabolic acidosis systemically [58].

\subsection{Disrupted microbiome in gout: Possible rôle in fungal infection}

Gout, like many other diseases, is associated with an abnormal distribution of the gut microbiome. A recent study used a gene microbiome profile to develop a diagnosis protocol for gout, which was termed a microbial index of gout (MiG). It was able to distinguish gout patients from control patients with better accuracy than uric acid levels ( $89 \%$ vs $71 \%$ accuracy) [59]. The study authors found, in particular, that multiple species of Bacteroides were enriched in gout patients, whereas Faecalibacterium prausnitzii, a major producer of butyrate, was under-represented. Microbial xanthine dehydrogenase, the enzyme that produces uric acid, was enriched in association with gout, whereas microbial allantoinase, an enzyme that degrades it, was depleted. A decreased level of butyrate biosynthesis was found to be a feature shared with both liver cirrhosis and type 2 diabetes, along with lessening of Faecalibacterium parusnitzii.

Bacteroides caccae is a recognized biomarker of IBD [60]. Liver cancer, diabetes and IBD are three of the many diseases found by Swanson et al. to be rising at an alarming rate in step with the rise in glyphosate usage on core crops in the USA [41]. The correlation coefficients with glyphosate for liver cancer, diabetes and IBD were $0.960\left(P\right.$-value $\left.=4.6 \times 10^{-8}\right), 0.971(P$-value $=$ $\left.8.3 \times 10^{-8}\right)$ and $0.938\left(P\right.$-value $\left.=7.1 \times 10^{-8}\right)$, respectively.

Genetic defects in the gene for the ATP-binding cassette $(\mathrm{ABC})$ transporter, $\mathrm{ABCG} 2$, are linked to hyperuricaemia and gout [61]. This urate transporter is found in both the intestines and the kidneys, and it appears that impaired excretion from the intestines is a major factor in the disease pathology. It may be significant with respect to potential glyphosate disruption of this enzyme that ABCG2 has a highly conserved glycine in the fifth transmembrane helix near the extracellular surface. In the Drosophila variant of ABCG2, substitution of either leucine or glutamic acid for this glycine residue resulted in the retention of the transporter in the endoplasmic reticulum, probably due to impaired dimerization and impaired glycosylation [62].

A fascinating paper from 1992 proposing a link between gout and fungus infection provides compelling arguments to support such a theory [63]. While the microbiome study discussed above [59] did not mention any link to fungal infection, it is likely that the study was not designed to detect fungal growth. However, the fact that the authors found low butyrate expression is supportive of a potential yeast problem. Butyrate is a known histone deacetylase (HDAC) inhibitor, and HDAC inhibition has been shown to impair fungal growth. A study by Nguyen et al. on cultured yeast strains of Candida and Cryptococcus published in 2011 showed that sodium butyrate (SB) strongly inhibited yeast growth in a concentration-dependent manner [64]. SB inhibited known virulence traits such as filamentation in C. albicans and capsule formation in C. neoformans. It also significantly decreased yeast biofilm formation and enhanced the antifungal activity of azole drugs. Finally, it enhanced the effectiveness of macrophages to kill yeast by increasing their phagocytic rate and enhancing their ability to produce inducible nitric oxide.

Costantini provided multiple arguments to support his hypothesis of a link between gout and fungal infection and/or fungal toxins [63]. Multiple species of fungus have been found to induce gout in animals, especially geese [65], chickens and turkeys [66,67], where gout has been 
attributed to exposure to the mycotoxins oosporein [66, 67] and ochratoxin [68]. Extracts from yeast cell walls containing $\beta$-glucans can provoke severe arthritis in a breed of mice with genetic susceptibility, and antibiotic treatment targeting fungi is protective [69]. The association of alcohol consumption, and especially beer consumption [70], with gout could be due in part to the fact that beer is produced using brewers' yeast, Saccharomyces cerevisiae. Beer contains high levels of urate and can also contain ochratoxin, a mycotoxin produced by Saccharamyces [71]. Ochratoxin, as well as other mycotoxins, disrupts the tight junction proteins in the gut barrier, causing leakage of materials from the gut lumen into the general circulation [72]. It may be that mycotoxins infiltrate urate crystals and induce an inflammatory reaction in macrophages, endocytosing the crystals.

The colonic mucosa are protected by sulfated mucin glycoproteins (mucins), which are produced by the colonic epithelial cells. These mucins offer important protection from microbial invasion. It has been demonstrated that they reduce the virulence of Candida by suppressing their attachment to human cells, preventing the formation of biofilm and suppressing the development of cell-penetrating hyphae [73]. Butyrate enhances the synthesis of mucins [74], hence butyrate deficiency leads to mucin deficiency.

Multiple strains of Lactobacillus brevis derived from traditional Bulgarian fermented dairy products were able to suppress the growth of Aspergillusin vitro [75]. Furthermore, Lactobacillus casei has been found experimentally to reduce the inflammatory response in a mouse model of arthritis [76]. Enzymes that degrade urate to urea are prominent in Lactobacillus species [59]. Lactobacillus is a common member of the human intestinal microbiota, but it is unusual in that it utilizes manganese but not iron in enzymatic catalysis [77]. Iron overload causes iron-dependent species to outcompete Lactobacillus [78]. Lactobacillus species are preferentially killed by glyphosate, likely due in part because of their strong dependency on manganese, which glyphosate chelates, making it unavailable [79].

Fungi make up only a fraction of a percent of the intestinal microbiota, and their potential rôle in disease is not yet well characterized. IBD shows a microbial profile that resembles the profile in gout, and it is associated with a higher diversity of fungal species in the colon [80]. Fungal diseases have emerged as an important health problem in the USA in recent decades [81]. A dramatic increase in mortality due to mycoses, attributed mainly to Candida, Aspergillus and Cryptococcus, occurred between 1980 and 1997, rising from 1,557 deaths in 1980 to 6,534 deaths in 1997 . The number of cases of fungal- induced sepsis in the USA increased by $207 \%$ between 1979 and 2000 [82].

Aflatoxin B1, produced by Aspergillus, is a common contaminant in multiple foods, including peanuts, cottonseed meal, corn and other grains [83] as well as animal feed [84]. While glyphosate suppresses the growth rate of many bacteria, it has been shown to increase the growth rate of Aspergillus [85]. In fact, multiple species of fungi are able to metabolize glyphosate, and this can give them a growth advantage [86]. Aflatoxin B1 caused numerous clusters of urate crystals in exposed macaques [87]. Remarkably, Aspergillus has an alternative pathway for the metabolism of purines to urate that does not require molybdenum as a cofactor [88]. This variant enzyme is found only in fungi. A study testing the growth rate of Aspergillus niger on different carbon sources, including fructose, glucose, sucrose, maltose and starch, found that $A$. niger grew best on fructose compared to all the others [89]. Fructose is a well-established risk factor for gout [90]. A study based in New Zealand found that Caucasians consuming four or more drinks sweetened with high-fructose corn syrup per day had a nearly sevenfold increased risk for gout compared to those consuming none [91]. It has been argued that fructose metabolism by the gut bacteria is disrupted by glyphosate, in part due to its blockage of the shikimate pathway [49], and this would result in an excessive concentration of fructose delivered to the colon, which would likely promote the growth of fungi.

Costantini also argued that multiple drugs used to treat gout are actually very effective as antifungal drugs as well [63]. Colchicine, one of the most common drugs used to treat gout, is an antitubulin drug, and its mode of action is the same as that of the antibiotic drug Griseofulvin, which is used to treat yeast infections. Patients with gout experienced dramatic improvements in acute gout following administration of griseofulvin specifically to treat a superficial fungal infection.

Meat, fructose and alcohol are recommended to be avoided in a "Candida diet," and they are all linked to acute gout attacks. Fructose is an excellent fuel source for yeast, promoting growth. An alkaline colon, induced by the breakdown of nitrogen in meat to ammonia, is conducive to fungal overgrowth. Alcohol is toxic and it tends to preferentially harm the bacteria in the gut, disrupting the bacteria/yeast balance.

\subsection{Molybdenum deficiency and sulfite}

Dietary advice for gout includes decreasing food sources of purines such as organ meats (e.g., liver, kidney), seafood and red meat, decreasing alcohol and fructose consumption, and increasing legumes and nuts. Fruits 
and meats are poor sources of molybdenum, whereas nuts and legumes are good sources. Hence, adherence to this dietary advice would lead to an increase in dietary molybdenum.

Three important enzymes using molybdenum as a catalyst are xanthine oxidase, aldehyde oxidase and sulfite oxidase. If xanthine oxidase and aldehyde oxidase are in high demand in the gut due to dietary purines and alcohol, then their overproduction can lead to a deficiency in sulfite oxidase, because these other enzymes trap most of the molybdenum that is available. Glyphosate may be a factor here as well, because it is a potent chelator of $2+$ cations [92] (glyphosate was first patented as a metal chelator in 1964 by the Stauffer Chemical Company). A deficiency in sulfite oxidase will lead to two problems: insufficient sulfate and toxic build-up of sulfite.

The gut microbiome in IBD resembles that in gout. A recent paper has proposed that a major factor in the development of IBD is disulfide bond splitting in the mucins by excess sulfide in hydrogen sulfide $\left(\mathrm{H}_{2} \mathrm{~S}\right)$ produced by sulfur-reducing bacteria such as Desulfovibrio [93]. A deficiency in sulfite oxidase would encourage the growth of microbes able to reduce highly toxic sulfite to less toxic $\mathrm{H}_{2} \mathrm{~S}$, which would then disrupt the tight barrier that keeps the microbes and the toxins they produce from penetrating into the general circulation. The sulfomucins in the colon normally contain a highly viscous and sterile inner layer, but this layer gets breached in the presence of excess $\mathrm{H}_{2} \mathrm{~S}$. Excess sulfide has been found in the intestine in association with IBD $[94,95]$.

A further factor contributing to $\mathrm{H}_{2} \mathrm{~S}$ synthesis is glyphosate's ability to suppress an assimilatory sulfite reductase enzyme expressed by E. coli and other microbes in the gut [96]. An appendix to a paper by Lu et al. provides a list of enzymes whose expression was inhibited multiplefold by glyphosate [96]. Both the $\alpha$ and $\beta$ subunits of sulfite reductase were included in the appendix, as shown in Table 1.

Table 1. Reduced activity of two subunits of assimilatory sulfite reductase in E. coli exposed to glyphosate (see [96] for details).

\begin{tabular}{lc}
\hline Enzyme & Fold reduction \\
\hline Sulfite reductase, flavoprotein $\beta$ subunit & -4.55 \\
Sulfite reductase, $\alpha$ subunit & -3.23 \\
\hline
\end{tabular}

Sulfite reductase deficiency in plants is associated with increased oxidative stress [97], which is also seen in gout. Sulfite reductase contains a haem group, and haem synthesis is also suppressed by glyphosate [79,98]. This enzyme in $E$. coli is essential for the synthesis of methionine, an essential amino acid in humans because our own cells are unable to synthesize it. Hence, suppression of this enzyme leads to methionine deficiency in addition to the accumulation of toxic amounts of sulfite in the gut. Glyphosate's known inhibition of methionine synthesis in plants [99] may plausibly be due at least in part to suppression of assimilatory sulfite reductase.

One can hypothesize that, as a consequence of $E$. coli's impaired ability to incorporate the sulfur atom of sulfite into organic sulfur compounds, the dissimilatory sulfite reductase of Desulfovibrio produces $\mathrm{H}_{2} \mathrm{~S}$ from sulfite instead. It may be significant that the chromophores in E. coli's assimilatory sulfite reductase contain bound iron, whereas it appears that the dissimilatory sulfite reductase in Desulfovibrio does not [100], and therefore may be less susceptible to inhibition through glyphosate chelation of iron. Desulfovibrio competes with butyrate-reducing microbes for carbon sources [101], and thus its overgrowth could also account for the butyrate deficiency observed in association with the gout microbiome.

Furthermore, impaired sulfite oxidase leads to sulfate deficiency, and sulfates are essential in the sulfomucins for maintaining the highly viscous "exclusion zone" water of the inner layer [102]. Chondroitin sulfate, an important component of the sulfomucins, has been used effectively as a therapeutic agent for IBD in both humans and dogs $[103,104]$.

\subsection{Endothelial nitric oxide synthase}

Endothelial nitric oxide synthase (eNOS) plays a vital rôle in regulating blood flow, in part through production of nitric oxide (NO) following signaling by calcium uptake and phosphorylation of calmodulin, a regulatory protein [105]. However, eNOS is also capable, especially under hypertensive conditions, of producing superoxide instead of NO in an uncoupled mode [106]. This can lead, through reaction with $\mathrm{NO}$, to the production of peroxynitrite $\left(\mathrm{ONOO}^{-}\right)$, an extremely destructive oxidizing agent. It has been proposed that eNOS is a "moonlighting" enzyme, switching between oxidizing nitrogen or sulfur depending on the external environment [102, 107]. Superoxide is used to oxidize sulfur when eNOS is bound to caveolin in the membrane, whereas phosphorylated calmodulin induces eNOS to detach from the membrane and synthesize NO instead, following phosphorylation.

$\mathrm{NO}$ and $\mathrm{SO}_{2}$, produced alternately by eNOS depending on the environment, both spontaneously oxidize, to nitrite and sulfite respectively, and enzymatic action by nitrate synthase and sulfite oxidase further oxidizes them, to nitrate and sulfate respectively. Nitrite is capable of eroding the extracellular matrix proteins, 
which then allows fragments to bind to oxidized LDL for subsequent endocytosis. These fragments contain heparan sulfate, which is very useful in the lysosomes for maintaining the acidic environment needed to safely metabolize the contents of LDL using the Fenton reaction invoked by iron. In a sufficiently acidic environment (buffered by sulfuric acid) the reaction product is water instead of hydrogen peroxide $\left(\mathrm{H}_{2} \mathrm{O}_{2}\right) ; \mathrm{H}_{2} \mathrm{O}_{2}$ is a dangerous oxidizing agent that can cause collateral damage.

The sulfate produced by eNOS when it is membrane-bound can be combined with modified sugar molecules and attached to glycosylated proteins to produce sulfated glycosaminoglycans (sGAGs) in the glycocalyx. These will then be released by the cell to restore the extracellular matrix that was eroded during the nitrate cycle of eNOS activity. Thus, there is a continual cycle of destruction and replenishment of the extracellular matrix proteins in the endothelial wall.

The amount of NO that is synthesized by eNOS is regulated by blood flow, in an elegant process that takes advantage of electromagnetic fields induced by the flowing blood. Red blood cells are negatively charged, in part due to sialic acid in the membrane glycoproteins [108] and in part due to cholesterol sulfate [102, 107]. The movement of negatively charged particles engenders an electrokinetic vascular streaming potential (EVSP), which is proportional to the pressure and to the zeta potential, which depends on the negative charge density, and inversely proportional to the viscosity of the medium. An increase in the EVSP induces an increase in NO synthesis by endothelial cells [109]. Thus, high viscosity and low negative charge density in the RBC membrane due to insufficient cholesterol sulfate will both contribute to a weakening of the EVSP; it can be compensated by elevated blood pressure, which, like high viscosity, is associated with gout.

\subsection{The Hofmeister series and blood viscosity}

The Hofmeister effect is an important concept in biophysics; it puts small solutes on a scale according to the degree to which they support the solubility of proteins in water. Molecules that increase solubility are chaotropes, whereas those that promote salting out or crystallization are kosmotropes $[110,111]$. Chaotropes tend to destructure water, decreasing its viscosity, whereas kosmotropes promote the formation of a gel-like, highly viscous crystalline form of water akin to ice.

Sulfite oxidase and nitrate reductase are an interesting pair of enzymes with shared characteristics. As discussed, sulfite oxidase produces sulfate from sulfite, whereas nitrate reductase reduces nitrate to nitrite. Both are members of a large class of enzymes called molybdenum oxotransferases. Notably, xanthine oxidase, the enzyme that produces urate from precursor purines, is also a member of this class. While mammals do not possess nitrate reductase per se, xanthine oxidase expresses nitrate reductase activity in the presence of NADH [112, 113]. Inflamed human synovial tissues can produce NO even in the presence of NOS inhibitors, and it has been demonstrated that xanthine oxidase is responsible for this production, via nitrate reduction [113]. Furthermore, enhanced expression of xanthine oxidase is observed in inflamed synovial fluids, produced by endothelial cells [114].

In addition to their dependency on molybdenum and the presence of a haem group sensitive to glyphosate disruption, one remarkable feature of this class of enzymes is sensitivity to the viscosity of the medium. A hinge region depends on low viscosity to induce efficient electron transfer between the haem and the molybdenum domains $[39,40]$. Thus, these enzymes are more active when the viscosity is low.

This design is very interesting, because nitrate and sulfate have opposite effects on blood viscosity according to the Hofmeister series. Nitrate, being a chaotrope, destructures water, leading to a lowering of viscosity; whereas sulfate, a kosmotrope, structures water, increasing viscosity [111]. In addition to maintaining tight physiological control of blood $\mathrm{pH}$, it is also necessary to maintain blood viscosity in a tight range to protect from haemorrhage at low viscosity and thrombosis at high viscosity. We propose that sulfite oxidase and nitrate reductase play a critical rôle in this regulation, especially post-prandially, through the ability to quickly alter sulfate and nitrate levels in the blood. Elevated levels of glucose [36] and triglycerides [35] increase viscosity, which needs to be offset by a high ratio of free nitrate to free sulfate in the blood. Glucose levels are correlated with blood viscosity even in non-diabetics [36]. The rise in viscosity induced by glucose and triglycerides will lower the activity of sulfite oxidase and nitrate reductase, thus inducing a rise in the nitrate/sulfate ratio that will help to lower the viscosity. Insulin, induced by a rise in serum glucose, induces the release of NO by endothelial cells, which is oxidized to nitrate to further increase its level in the blood.

Since high serum triglycerides are a trigger for gout, and gout is also associated with both diabetes and cardiovascular disease, it seems clear that high blood viscosity may be a key factor in triggering gout.

\subsection{Sulfite oxidase deficiency}

A glycine residue at position 473 is strictly conserved in all sulfite oxidase (SO) proteins thus far isolated, including plant and bacterial isoforms [115]. If the glycine residue in 
SO is replaced with aspartate, the enzyme is impaired in its ability to form a dimer, which leads to a severe impairment both in its ability to bind sulfite and in catalysis, reducing the reaction rate by five orders of magnitude compared to the wild type [115]. Both the charge and the large size of an aspartate residue contribute to the severe effects, by causing partial misfolding and monomerization, and attenuating substrate binding and catalytic efficiency. Glyphosate substitution for this crucial glycine residue can also be expected to disrupt the enzyme function in a similar way.

Molybdenum deficiency is another consideration with SO; glyphosate's chelation of $2+$ cations make molybdenum a probable target of glyphosate [116]. A severe lack of SO's molybdenum cofactor has profoundly adverse effects on development (including mental retardation, microcephaly and spasticity) [117]. An encephalopathic response to hypoxic ischaemia may also be due to molybdenum cofactor deficiency $[118,119]$.

The hinge region in SO depends on low viscosity to induce efficient electron transfer between the haem and the molybdenum domains $[39,40]$. As already discussed, high serum viscosity can be expected to be a systemic problem in association with gout, due to the fact that it is linked to haemochromatosis, elevated triglycerides and hyperglycaemia, all of which increase serum viscosity.

A recent experiment exposing rats to relatively high doses of glyphosate over seven days revealed a specific effect on lipid metabolism in the liver; it was hypothesized to be due to the synthesis of glyoxylate as a by-product of glyphosate degradation by gut microbes [120]. Specifically, fatty acid oxidation was inhibited, diverting fatty acids towards other pathways that lead to elevations in serum triglycerides and cholesteryl esters. While the dose was higher than that expected from contaminated food, the authors thought that a lower dose over a longer interval could produce a similar result.

It is interesting to note that the viscosity of synovial fluid in association with rheumatoid and osteoarthritis is significantly lower in arthritic patients, along with a significantly diminished concentration of hyaluronic acid, which raises viscosity [121]. The lowered viscosity should promote activation of SO within the joint, which can support sulfate synthesis there.

A reason for sulfite toxicity was proposed in [122]: $\mathrm{Fe}^{3+}$-cytochrome $\mathrm{c}$ in the inner membrane of mitochondria will react with sulfite to produce the sulfite radical, catalysed by $\mathrm{H}_{2} \mathrm{O}_{2}$ [122]. This in turn can cause oxidative damage to proteins, lipids, RNA and DNA, believed to be the main mechanism of toxicity of sulfite to tissues. Cytochrome c oxidase plays an essential rôle in the electron transport chain in mitochondria. It receives an electron from each of four cytochrome c molecules, and transfers them to one oxygen molecule, converting it to two molecules of water. As described in [48], cytochrome $\mathrm{c}$ oxidase has an oxyanion hole that channels the oxygen molecule to the active site, and maintenance of this hole has a strong glycine dependency. Thus it is possible that impairments in glyphosate-contaminated cytochrome $\mathrm{c}$ oxidase lead to increased toxicity of sulfite in mitochondria.

\subsection{Homocysteine thiolactone}

Gout is associated with markedly elevated serum homocysteine [123]. In the presence of methionine deficiency, homocysteine can erroneously substitute for methionine during protein synthesis, and the correction of this coding error results in the release of homocysteine thiolactone, a toxic variant of homocysteine. However, in the presence of superoxide, and with catalytic assistance from retinoic acid and ascorbate, homocysteine thiolactone can be processed to $\alpha$-ketobutyrate, releasing sulfite and ammonia (see Fig. 1 in [124]). Thus it could serve as a precursor to sulfate synthesis directly in the artery wall, but the requirement for superoxide will result in additional oxidative stress.

Glyphosate has been shown to inhibit methionine synthesis in plants, in addition to the aromatic amino acids [99]. We have already discussed glyphosate's inhibition of assimilatory sulfite reductase in the common gut microbe $E$. coli, and this is an essential enzyme in the methionine synthesis pathway. Furthermore, this same study of glyphosate's effects on $E$. coli enzyme expression revealed strong suppression of 3'-phosphoadenosine 5'phosphosulfate (PAPS) reductase, another enzyme that is essential for the de novo synthesis of methionine from sulfate [95]. Human methionine supply depends on its synthesis by the gut microbiome or dietary methionine, since human cells are unable to synthesize it.

Homocysteine thiolactone can be converted back to homocysteine via the enzyme paraoxonase type 1 (PON1), and it has been suggested that this is the original function of PON1, an enzyme that also detoxifies organophosphates. However, oxidative stress inactivates PON1 [125]. A study comparing 49 gout patients with 42 healthy controls revealed that gout is associated with a reduced PON1 activity $(P<0.01)$ along with reduced superoxide dismutase 1 (SOD1) activity $(P<0.05)$ and an increase in plasma levels of malondialdehyde, a marker of oxidative stress $(P<0.01)$, and oxidized LDL $(P<0.01)$ [126]. Homocysteinylation of LDL increases its susceptibility to oxidation and facilitates its uptake by macrophages, and homocysteinylated LDLs elicit an autoimmune response $[127,128]$. 


\subsection{Nonalcoholic fatty liver disease and iron overload}

Nonalcoholic fatty liver disease (NAFLD) is strongly associated with insulin resistance, the metabolic syndrome, cardiovascular disease and gout $[129,130]$. It progresses over time towards steatohepatitis and hepatic fibrosis, then cirrhosis and, ultimately, liver failure. Both serum urate levels and serum ferritin (an acute phase reactant related to iron homeostasis) are biomarkers that predict NAFLD. Its prevalence in the general population ranges between $20 \%$ and $30 \%$, parallelling the worldwide epidemics in obesity and type 2 diabetes $[131,132]$.

Schreinemachers and Ghio have proposed that iron chelation may play a major rôle in the pathology associated with multiple environmental toxins, including glyphosate [133]. They argue that this leads to functional iron deficiency and disrupted iron homeostasis, including elevated serum ferritin, which is linked to diabetes. Glyphosate exposure can be predicted to lead to both iron deficiency and iron toxicity (due to the Fenton reaction), because biological iron transport mechanisms are disrupted by glyphosate [48].

A 2009 study exposed rats to glyphosate and Roundup and looked specifically at the effects on rat liver, but also measured serum levels of uric acid [134]. After a two-week delay, uric acid levels in the glyphosate-treated group $(4.1 \mathrm{mg} / \mathrm{dL})(135 \mathrm{mg} / \mathrm{kg})$ and, especially, in the Roundup-treated group $(6.4 \mathrm{mg} / \mathrm{dL})(270 \mathrm{mg} / \mathrm{kg})$ were significantly higher than in the control group $(2.6 \mathrm{mg} / \mathrm{dL})$. The increase in uric acid levels was associated with an increase in both cholesterol and triglyceride levels in both the glyphosate- and Roundup-treated groups. Concurrently, glutathione levels were lowered in both treatment groups. Lipid peroxidation in the rat liver increased dramatically in the treatment groups compared to the control group (control: $2.6 \mu \mathrm{mol} / \mathrm{g}$, Roundup: $19.0 \mu \mathrm{mol} / \mathrm{g}$, glyphosate: $13.9 \mu \mathrm{mol} / \mathrm{g}$ ); lipid peroxidation leads to hepatic necrosis. ${ }^{4}$

We have already mentioned that an elevated haematocrit is associated with gout [34]. Elevated haemoglobin translates into elevated iron stores. In a study investigating a possible relationship between high serum urate and iron overload, it was found that $20.7 \%$ of those with high uric acid had high ferritin levels versus only $8.8 \%$ of those with low serum urate $(P<0.001)[136] .^{5}$ Another study on healthy adults, both male and female, found a direct correlation between serum ferritin levels and serum urate levels, independent of gender, age, race/ethnic group, body mass and alcohol consumption [137]. The effect of meat consumption on gout may be ascribed to iron rather than to purine metabolism. Phlebotomy to reduce iron load was successful as a treatment method for 12 patients with gout [138]. During a 28-month follow-up period, effects ranged from marked reduction in both frequency and severity of gout attacks to complete remission.

Xanthine oxidase activity is increased in the presence of iron, increasing urate levels. A number of mechanisms mediate this increase, including multiple iron regulatory elements in the enzyme and an indirect effect mediated through an inflammatory response to free iron. Furthermore, iron chelates, particularly haemoglobin, scavenge NO, preventing it from inhibiting the expression of xanthine oxidase [137]. Since urate is a powerful antioxidant, its synthesis can ameliorate the ROS induced by free iron through the Fenton reaction.

In our view, iron is essential for the gouty joint to be able to follow through with its activities to supply sulfate to the vasculature. Excessive free iron likely plays a significant rôle in gout, through induction of ROS and the resulting signaling cascade. Urate crystals adsorb $\mathrm{Fe}^{3+}$ in vitro, and the inflammatory response induced by urate crystals is suppressed by iron chelators [139]. There is a hidden benefit to iron availability since iron is needed for the synthesis of haem, to be incorporated into sulfite oxidase, cytochrome c oxidase and nitric oxide synthase. Iron accumulates in the subintima of the synovial membrane in gouty joints [140]. Gamma glutamyl transpeptidase (GGT), present in the arthritic joint, reduces iron from the $3+$ to the $2+$ oxidative state, facilitating the uptake of transferrin-bound iron [141].

Excessive iron may also contribute to fungal infections. A study on patients with haematological malignancies showed that increased transferrin saturation values and high serum ferritin were associated with increased risk to fungal infection [142]. Increased bone marrow iron stores is an independent risk factor for invasive aspergillosis in patients with haematologic malignancies [143]. Excess iron increases the virulence and invasive potential of yeast in recurrent vulvovaginal candidosis [144], and iron depletion increases the susceptibility of Candida to antifungal drugs [145].

\subsection{GGT in the synovium: An explanation}

GGT is an enzyme that decomposes glutathione into its component amino acids (glycine, glutamate and cysteine) and it has been identified as a predictive biomarker of cellular antioxidant inadequacy, as well as both disease and mortality risks [146]. It has also been proposed as a marker for exposure to various environmental pollutants [147]. Glyphosate has been shown to increase the serum

\footnotetext{
${ }^{4}$ Furthermore, increases in TNF expression were observed in both treatment groups.

${ }^{5}$ Ferritin release from dying cells can explain high serum ferritin levels [135].
} 
levels of GGT in exposed mice [148]: both male and female mice, exposed to either 50 or $500 \mathrm{mg} / \mathrm{kg}$ body weight of Roundup for 15 days, had elevated GGT levels.

Here, we propose a novel rôle for GGT to disassemble glutathione so that the component amino acids can be used to restore sulfate levels in the vasculature, under conditions of vascular stress due to elevated serum viscosity. Cysteine is the precursor to sulfate, and glutamate and glycine are used to synthesize the pyrrole ring as a component of haem, to support multiple enzymes involved in sulfur oxidation to sulfate.

Consistent with this idea are the results of Sedda et al., who studied 150 subjects: 37 without, and 113 with one or more cardiovascular risk factors [149]. Fasting glucose levels, serum folate and vitamin concentrations fell within the normal range in the overall population. However, $18 \%$ of the men and $6 \%$ of the women had out-of-range GGT values. This investigation found GGT activity was inversely related to plasma glutathione $(P<0.001)$ and positively related to a number of cardiovascular risk factors, including male gender, malondialdehyde (an indicator of oxidative stress), serum glucose and plasma total cysteine.

The authors of a recent study using apolipoprotein E-knockout mice found that the addition of Atorvastatin to a high fat diet decreased LDL cholesterol levels in the blood, as expected, but also decreased the GGT expression in the plaque at the same time [150]. To us, this suggests that there is a reduced need for GGT to promote sulfate synthesis because there is insufficient cholesterol in the blood to be conjugated with it to form cholesterol sulfate. A relationship with significantly higher GGT values was recently observed among young Turkish adults with coronary atherosclerosis [151]. Compared to controls of a similar age (approx. 42 years), patients having atherosclerosis plaque burdens had significantly higher GGT, creatinine, total cholesterol, LDL-cholesterol, triglyceride, uric acid, HbAlc and hs-CRP levels, and significantly lower HDL-cholesterol levels.

Remarkably and unexpectedly, GGT levels were found to be extraordinarily high in the synovial fluid of several patients with rheumatoid arthritis [152]. Nine out of 50 patients examined had levels of GGT in the synovial fluid that were eightfold higher than the upper limit of the normal range. Overall, the 50 patients had on average a tenfold higher GGT activity in the synovial fluid compared to the average value among the controls. This was not associated with a similar rise in serum GGT, and it was confirmed that the GGT in the synovium was synthesized locally. GGT is an endogenous activator of toll-like receptor 4 (TLR4) [153]. TLR4 signaling, which induces an inflammatory cascade, has been found in male gout patients [154].
GGT is secreted under stress conditions from hepatocytes along with glutathione, and the glutathione is then processed in the external environment. Although it is generally believed that the main purpose of GGT is to support the transport of glutathione from one cell to another via a complex process of decomposition and reassembly, a much more logical explanation derives from the observation that these three amino acids together play an important rôle in promoting sulfate synthesis.

Glycine and glutamate, once freed from glutathione, can be taken up by a cell and used to produce haem. Studies on rat aorta have confirmed that haem is resynthesized from scratch in the vasculature to supply it to haem-containing enzymes [155]. The basic building block of haem is the pyrrole ring, which is synthesized de novo from glycine and glutamate (via succinyl coenzyme A).

There are several haem-containing enzymes that are involved in synthesizing sulfate. eNOS, which, when membrane-bound, synthesizes $\mathrm{SO}_{2}$, probably from thiosulfate and other persulfide precursors, contains a haem group. $\mathrm{SO}_{2}$ oxidizes spontaneously to sulfite, and sulfite oxidase, which further oxidizes sulfite to sulfate, also has a haem group. A haem group in cytochrome $\mathrm{c}$ in the mitochondria is essential for producing ATP, needed to produce the final product, $3^{\prime}$-phosphoadenosine- $5^{\prime}$ phosphosulfate (PAPS), the universal sulfate donor. Cysteine, via cysteine- $\gamma$-lyase, is a source of $\mathrm{H}_{2} \mathrm{~S}$, which can be oxidized to thiosulfate by the mitochondria [156] and thence to sulfate via eNOS, with assistance from sulfite oxidase in the final step.

The first and rate-limiting step in the synthesis of pyrrole is catalysed by $\delta$-aminolevulinic acid (ALA) synthase, which has been shown to be inhibited by glyphosate [48, 157], likely through competitive inhibition of glycine as substrate. Hence glyphosate contamination in the synovium would interfere with the synthesis of multiple enzymes involved in the pathway from sulfide to PAPS. There is even the possibility that glutathione itself is sometimes constructed with glyphosate in place of glycine, an ominous thought in terms of the implications of supplying glyphosate directly to the synovium embedded in a defective glutathione molecule.

\subsection{A rôle for testosterone and muscles}

Plasma urate likely plays an important rôle in buffering muscle urate supplies during strenuous exercise. The liver synthesizes urate from hypoxanthine, and releases it into the plasma. It is subsequently taken up by muscle cells to maintain their own supply. During vigorous exercise, muscle cells are exposed to oxidative stress, which spontaneously (non-enzymatically) oxidizes urate 
to allantoin [158]. The allantoin is released into the plasma and exported to the kidneys.

A single session of long-term high-intensity intermittent exercise can lead to a marked release of purines from the exercised muscle along with a reduction of the ATP levels in the muscle cells that persists for more than 90 minutes after exercise termination [159]. If plasma urate levels are sufficiently high during and after the exercise period, the muscle extracts urate from plasma to replenish internal stores.

The average serum levels of urate are significantly higher in men than in women, and this is believed to be due in part to the fact that testosterone influences the kidneys to retain urate whereas oestrogen allows more loss through the kidneys. There is a logical reason for this in that testosterone also induces increased muscle mass, and muscles require an internal buffer of urate to protect them from oxidative damage. A study on transgender males who were administered intramuscular testosterone replacement therapy elegantly demonstrated that serum urate levels are directly related to testosterone [160]. Furthermore, the level of serum creatinine, which to some extent represents the individual's muscle volume, was also strongly correlated with both urate levels and testosterone dosage. This suggests that the total amount of muscle mass plays an important rôle in regulating serum urate levels and, perhaps more importantly, that high serum urate is beneficial in protecting muscle tissues from damage.

Creatine plays an important rôle in muscle contraction by shuttling energy sources from different compartments around and providing buffering support for ATPase [161]. Creatine kinase (CK) in the mitochondrial intermembrane space regenerates phosphocreatine $(\mathrm{PCr})$ from mitochondrially generated ATP and creatine. PCr is shuttled to the cytoplasm, where it can be coupled to ATP-dependent processes, such as the acto-myosin ATPase and calcium ATPase involved in muscle contraction. Creatinine is a breakdown product of $\mathrm{PCr}$, and its level in the blood is usually proportional to total muscle mass. Creatinine is filtered out with little or no reabsorption in the renal glomeruli (an unusually high serum creatinine level is an indicator of damage to nephrons in the kidneys). Thus, elevated serum creatinine can be correlated with elevated serum urate in part as a consequence of kidney failure, when both creatinine and urate are retained by the failing kidneys.

\subsection{Impaired lipase activity and elevated serum triglycerides}

High serum lipids are associated with gout [162]. Heparin induces the release of lipoprotein lipase into the blood [163], hence heparin deficiency could contribute to low lipase expression. Lipase releases fats from triglycerides so that they can be taken up and metabolized by the cell. The activities of both postheparin plasma lipoprotein lipase and hepatic triglyceride lipase were found to be reduced in association with gout, and activity levels were inversely correlated with VLDL and LDL triglyceride levels [164]. The $\beta$-oxidation of fatty acids yields acetyl coenzyme A, and therefore it is possible that acetate deficiency derives from impaired fatty acid lipase activity.

As discussed previously, glyphosate exposure induces elevated serum lipids in rats due to impaired lipid metabolism [120]. A sequence homology search for lipases among multiple species revealed only one residue that was consistently conserved across all species of animals, and only one residue that was consistent across all species of plants [165]. In animal lipases, this conserved residue was a glycine at position 118 and among plants, the conserved residue was a glycine at position 358. Furthermore, a GHSAG sequence was conserved among lipases synthesized by multiple species of plants, fungi, and bacteria, although this sequence was not conserved in animal lipases. Thus, it can be predicted that glycine plays an essential rôle in the enzyme's function across all species. Glyphosate has been detected as a contaminant in porcine lipase, as reported in [50].

\subsection{ApoB and small acidic antioxidants}

It has been known at least since the 1980 s that ApoB, the apolipoprotein contained in LDL, is uniquely capable of resolving an acute gout attack [166]. ApoB suppresses superoxide generation and cytolysis by neutrophils, thus taming the inflammatory response. ApoB has four separate peptide sequences that are positively charged and therefore attracted to negatively charged heparin and heparan sulfate [167]. Normally, ApoB binds to heparan sulfate in the extracellular matrix of a cell, and is then endocytosed along with the bound heparan sulfate. The endosome eventually evolves into a lysosome, and this involves the acquistion of extra protons to induce an acidic environment that will enable digestion of the contents of the LDL particle for recycling. During the digestion process, desulfatases remove the sulfate ions from the heparan sulfate, thus buffering the acidic $\mathrm{pH}$ [168]. The heparin that is released by mast cells in response to the inflammatory response precipitated by urate crystals will also bind to ApoB in LDL, and can be used in place of heparan sulfate to supply the sulfate buffering in the lysosomes once the LDL particle is endocytosed. 
Impaired lysosomal function leads to the accumulation of lipofuscin, a biomarker of aging [169]. Lipofuscin accumulation can be reduced by mechanisms that increase the acidification of lysosomes by whatever means [170]. As shown in Table 2, there are several other small acidic antioxidants besides sulfate that may be able to substitute for sulfate in supporting the buffering of the acidic $\mathrm{pH}$ in the lysosomes. It has been shown that urate crystals also bind to ApoB in LDL, but heparin and heparan sulfate will outcompete them in binding affinities. Furthermore, ApoB has several lysine residues that can be subjected to acetylation. Inter alia, lysine acetylation prevents urate binding, and the acetate that is then brought into the cell as cargo can also serve as a buffering agent for the lysosomes. A recent study has shown that acetate supplementation does not reduce the magnitude of the initial inflammatory response in gout, but it accelerates the pace of resolution of the gout episode [171]. Dietary fibre works similarly, probably because it is metabolized to acetate and other short-chain fatty acids by anaerobic microbes in the colon. ${ }^{6}$

Table 2. $\mathrm{p} K_{\mathrm{a}}$ values for biologically active small acidic antioxidants.

\begin{tabular}{lc}
\hline Sulfuric acid (1) & $<1.0$ \\
Oxalic acid (1) & 1.23 \\
Sulfuric acid (2) & 1.92 \\
Lactic acid & 3.86 \\
Oxalic acid (2) & 4.19 \\
Acetic acid & 4.75 \\
Propionic acid & 4.87 \\
Uric acid & 5.8 \\
\hline
\end{tabular}

Both urate and heparan sulfate can protect the lysosomes from oxidative damage due to the Fenton reaction. Lysosomes are often rich in iron, which assists in the redox reactions involved in breaking down cellular debris, but can also lead to severe cellular damage due to free radical products [173]. It is possible that oxalate [174] and citrate [175] can also support lysosomal buffering, although there is not at present any literature to support this idea.

We hypothesize that the inflammatory response in the gouty joint is induced in order to produce sulfate by oxidizing $\mathrm{H}_{2} \mathrm{~S}$, and then activate it by combining it with ATP. The activated sulfate is then conjugated with cholesterol to form cholesterol sulfate and then transferred to the heparan sulfate proteoglycans in the extracellular matrix by a sulfotransferase, facilitated by the intermediary PAPS. Heparan sulfate can then displace urate in binding to LDL, and in so doing abort the inflammatory cascade. Heparin protects lipids from freeradical peroxidation, but removal of both the $\mathrm{N}$ - and $\mathrm{O}$ sulfates greatly reduces its effectiveness [176]. Cholesterol sulfate can also be incorporated into the lipid monolayer of the LDL particle, and its negatively charged sulfate groups will also help shield the LDL particle from glycation and oxidation damage [102]. This will then reinstate LDL uptake by the liver and protect from cardiovascular disease.

A study on mice with streptozotocin-induced diabetes demonstrated that diabetes results in depletion of sulfated proteoglycans in the extracellular matrix in endothelial cells and in the liver [176]. This, in turn, impairs the uptake of lipids from $\beta$-VLDL particles. This can be predicted to lead to high serum triglycerides, which is a risk factor for gout [178]. The gouty joint essentially jump-starts the cycle by exploiting urate crystals, which also offer antioxidant protection in the lysosome, in place of heparan sulfate. The extra supply of sulfate ultimately produced by the gouty joint can help to correct sulfate deficiencies systemically, thus ameliorating the impaired lipid clearance and protecting lipids from oxidation and glycation damage.

Highly sialylated apoE is present in synovial fluid, likely produced by the resident macrophages, and it appears to protect from induction of an inflammatory attack by sodium urate crystals [179]. ApoE binds to urate crystals and inhibits urate crystal-induced neutrophil stimulation. ApoE also promotes cholesterol egress from macrophages and, importantly, sulfurylation of the glycocalyx [180]. It seems plausible that the cholesterol bound to ApoE is sulfated in transit and subsequently the sulfate anion is transferred to the glycocalyx, as proposed in [102].

\subsection{Cholesterol sulfate, heparin and PPAR- $\gamma$}

Peroxisome proliferator-activated receptor- $\gamma$ (PPAR- $\gamma)$ expression is rapidly induced in monocytes in response to monosodium urate crystals, with maximum expression observed four hours after exposure [26]. Synovial-tissuelocalized expression of PPAR- $\gamma$ by macrophages as well as by fibroblasts and endothelial cells is manifest in patients with rheumatoid arthritis [181]. Activation of PPAR- $\gamma$ by a derivative of prostaglandin D2 has been shown to suppress the immune response in rats [181]. PPAR- $\gamma$ ligands upregulate CD36 expression on monocytes, and this significantly reduces the production of cytokines. Thus, exposure to PPAR- $\gamma$ ligands following the inflammatory response may be the mechanism by which the inflammation is resolved.

\footnotetext{
${ }^{6}$ It is intriguing that lactate $\left(\mathrm{p} K_{\mathrm{a}} 3.86\right)$ supports lysosomal acidification and autophagy in tumour cells [172].
} 
The influx of neutrophils is a hallmark of acute gout [182]. Mast cells play an important rôle in amplifying the gouty inflammatory response, but probably also in the resolution. They release both prostaglandin D2 and heparin, among other products [183]. One feature of heparin is its ability to induce neutrophil infiltration. Heparin is the most highly sulfated molecule known to biology, and has a large negative charge, due to which it is able to detach bound kininogen from heparan sulfate proteoglycans in the extracellular matrix, and subsequently the detached kininogen is subjected to proteolysis to release active bradykinin, which in turn activates various signaling pathways that dilate vessels, promote neutrophil infiltration into the tissue site, and increase vascular permeability and tissue swelling [184].

Sulfated and disulfated oxysterols derived from cholesterol are also potent activators of PPAR- $\gamma$ [185]. The inflammatory response induces the release of ATP from cells and upregulates production of superoxide, which supports the oxidation of $\mathrm{H}_{2} \mathrm{~S}$ to sulfate by sulfite oxidase, and ATP can be combined with the sulfate to produce PAPS. Thus, the signaling response to urate crystals supports the synthesis of cholesterol sulfate which can then suppress inflammation via PPAR- $\gamma$ receptor activity, restoring the joint back to normalcy.

Cholesterol sulfotransferase type $2 \mathrm{~B}$ isoform $1 \mathrm{~b}$ (SULT2B1b) is a key enzyme in the synthesis of cholesterol sulfate. PPAR- $\gamma$ activators increase the activity of SULT2B1b in human keratinocytes. A 26-fold increase in the expression of SULT2B1b was induced by the PPAR- $\gamma$ activator, ciglitazone [126].

Cholesterol crystals, like urate crystals, can induce activation of the NLRP3 inflammasome, activating a proinflammatory response [186]. Cholesterol crystals have been found to coexist with urate crystals in gouty tophi in a joint or bursal cavity [187]. Cholesterol crystals can even lead to tophus formation and gout-like symptoms in the absence of urate crystals [188]. Sulfate, in its activated form as PAPS, either produced through chemical reactions induced by the inflammatory response or derived from the heparin released by mast cells, can be conjugated to cholesterol to solubilize these crystals. The cholesterol sulfate thus produced can then act as a ligand to PPAR- $\gamma$, thus resolving the inflammation and restoring the supply of cholesterol sulfate.

Cholesterol is not a normal part of the diet of rabbits, and experiments feeding cholesterol to rabbits demonstrate that they typically accumulate it in fat stores and in atherosclerotic plaque. Ying et al. found that L-lipoic acid supplementation can reverse these effects, leading to reduction in plaque levels and weight loss, reflecting the release of the cholesterol-containing fat stores [189].
This was associated with a reduction in the inflammatory response. We hypothesize that the sulfane sulfur in L-lipoic acid is the key ingredient that leads to these beneficial effects, allowing the cholesterol to be released as cholesterol sulfate.

\subsection{Nephrolithiosis and hyperoxaluria}

It has become clear in recent years that chronic kidney disease is a common occurrence among relatively young agricultural workers [190]. The form of kidney disease not necessarily associated with diabetes or hypertension has been termed "chronic interstitial nephritis in agricultural communities" (CINAC), and is also referred to as Mesoamerican nephropathy [191]. It is currently the most common cause of death among men in El Salvador. Researchers investigating the condition in Sri Lanka have concluded that glyphosate, working together with nephrotoxic metals, is a major causal factor [192], and this has caused the government of Sri Lanka to ban glyphosate usage in agriculture. Urate crystals are commonly found in the urine of sugar cane workers from El Salvador, and it was proposed by Roncal-Jimenez et al. that injury to renal tubules by the crystals could be a major causal factor in CINAC [193]. They further argued that the underlying initiating condition could be muscle damage due to intense exercise in a hot climate, causing excess urate synthesis, as discussed previously. Sugar cane in El Salvador is commonly sprayed with glyphosate right before harvest, so glyphosate exposure is prima facie implicated as a contributing factor to the disease.

The prevalence of nephrolithiasis has increased substantially in the USA over the past two decades. A population-based study in South Carolina showed that annual incidence increased by $1 \%$ annually from 206 to 239 per 100,000 from 1997 to 2012 [194]. Calcium oxalate crystals are the main source of kidney stones in urolithiasis. However, about one- third of patients with calcium stones have hyperuricosuria [195].

High concentrations of uric acid in the urine induce an increased risk to the formation of calcium oxalate stones [196]. Excessive urinary sulfate induces an acidic environment that further favours crystal formation. In vitro, the addition of urate to urine greatly increases the rate of precipitation of calcium oxalate crystals. The mechanism could be due to a "salting out" effect [197], or to epitaxy, the formation of one crystal on top of another seed crystal of differing origin [198].

Alanine:glyoxylate aminotransferase (AGT) is a pyridoxal 5'-phosphate(PLP)-dependent enzyme, which catalyses the reaction that produces pyruvate and glycine from L-alanine and glyoxylate [199]. Defective versions 
of this enzyme are associated with primary hyperoxaluria and associated nephrolithiasis. This is because glyoxylate is then redirected down a degradation pathway that leads to oxalate. It has been previously mentioned that glyoxylate is a degradation product of glyphosate in pathways supported by gut microbes [120]. Glyphosate treatment increased glyoxylate levels in rat liver by more than twofold in those experiments.

AGT has a highly conserved glycine residue at position 161, which has been linked to primary hyperoxaluria when mutated to arginine, cysteine or serine [199]. Furthermore, another glycine residue at position 41 is also vulnerable to mutations leading to hyperoxaluria [200]. In both cases, it appears that the mutated version is vulnerable to an increased rate of degradation and is prone to electrostatically-driven aggregation in the cell cytoplasm $[199,200]$. Substitution of glyphosate for either glycine can be expected to also lead to a defective version of the enzyme.

Thus, it is plausible that the overproduction of both oxalate and urate due to glyphosate's effects can explain the rise in nephrolithiosis in addition to the rise in gout over the past two decades.

\section{CONCLUSIONS}

The prevalence of gout has been rising alarmingly in multiple countries in the industrialized world in the past two decades, in parallel with the rise in the use of glyphosate as an herbicide. Here, we make a case for glyphosate's disruption of sulfate supplies, systemically, as an underlying aetiological factor associated not only with gout, but also with multiple other chronic diseases associated with gout, whose prevalence is also alarmingly on the rise in these same countries. These include diabetes, obesity, hypertension, fatty liver disease and lipid disturbances linked to cardiovascular disease, elevated triglycerides and an elevated ratio of LDL to HDL. We show how glyphosate could plausibly cause these deficiencies in sulfate through its disruption of the gut microbiome, leading to an overgrowth of fungi and sulfur-reducing species like Desulfovibrio along with a deficit in butyrate-producing microbes. Glyphosate, in part through metal chelation and in part through its insidious ability to substitute for glycine during protein synthesis, disrupts the function of multiple enzymes associated with sulfate homeostasis. A key trigger for an acute gout attack is high serum viscosity, associated with a high haematocrit and elevated serum LDL and triglycerides. We describe how sulfate deficiency can lead directly to metabolic disorders, immune deficiency and impaired blood flow.
In this paper, we propose that gout is a disease process that has a beneficial outcome in the production of sulfate and its conjugation to carrier molecules that are then exported back into circulation, such that sulfate supplies to the vasculature are renewed, averting disaster manifested as either haemorrhage or thrombosis. The signaling mechanisms orchestrating the activities in the gouty joint, while initially necessitating the production of damaging reactive oxygen species, eventually lead to resolution, along with improved sulfate bioavailability in the circulation. As sulfate supplies are renewed, heparan sulfate can become available to support the metabolism of LDL particles in the lysosomes of immune cells infiltrating the synovial fluid environment, as well as in the tissue cells in the joint. In concert, the immune cells succeed in renewing their own sulfate supplies, which both strengthens the immune system and improves vascular health.

\section{ACKNOWLEDGMENT}

This research is supported in part by Quanta Computers, Taiwan, under the auspices of the Qmulus project.

\section{REFERENCES}

1. Al-Allaf, A.-W. Gout: evidence based update with new therapeutic strategies. Sudan Med. J. 48 (2012) 165-175.

2. Urano, W., Yamanaka, H., Tsutani, H., Nakajima, H., Matsuda, Y., Taniguchi, A., Hara, M. and Kamatani, N. The inflammatory process in the mechanism of decreased serum uric acid concentrations during acute gouty arthritis. J. Rheumatol. 29 (2002) 1950-1953.

3. Pascual, E., Addadi, L., Andrs, M. and Sivera, F. Mechanisms of crystal formation in gout: a structural approach. Nature Rev. Rheumatol. 11 (2015) 725-730.

4. Jin, M., Yang, F., Yang, I., Yin, Y., Luo, J.J., Wang, H. and Yang, X.F. Uric acid, hyperuricemia and vascular diseases. Frontiers Biosci. 17 (2012) 656-669.

5. Albrecht, E., Waldenberger, M., Krumsiek, J., Evans, A.M., Jeratsch, U., Breier, M., Adamski, J., Koenig, W., Zeilinger, S., Fuchs, C., Klopp, N., Theis, F.J., Wichmann, H.E., Suhre, K., Illig, T., Strauch, K., Peters, A., Gieger, C., Kastenmüller, G., Doering, A. and Meisinger, C. Metabolite profiling reveals new insights into the regulation of serum urate in humans. Metabolomics 10 (2014) 141-151.

6. Kim, S.Y., Guevara, J.P., Kim, K.M., Choi, H.K., Heitjan, D.F. and Albert, D.A. Hyperuricemia and risk of stroke: a systematic review and meta-analysis. Arthritis Rheumatol. 61 (2009) 885-892.

7. Sluijs, I., Beulens, J.W., van der A, D.L., Spijkerman, A.M., Schulze, M.B. and van der Schouw, Y.T. Plasma uric acid is associated with increased risk of type 2 diabetes independent of diet and metabolic risk factors. J. Nutr. 143 (2013) 80-85.

8. Filiopoulos, V., Hadjiyannakos, D. and Vlassopoulos, D. New insights into uric acid effects on the progression and prognosis of chronic kidney disease. Renal Failure $\mathbf{3 4}$ (2012) 510-520. 
9. de Oliveira, E.P. and Burini, R.C. High plasma uric acid concentration: causes and consequences. Diabetol. Metabol. Syndrome 4 (2012) 12.

10. Puddu, P., Puddu, G.M., Cravero, E., Vizioli, L. and Muscari, A. The relationships among hyperuricemia, endothelial dysfunction, and cardiovascular diseases: molecular mechanisms and clinical implications. J. Cardiol. 59 (2012) 235-242.

11. Kawano, Y. Uric acid and blood pressure. Circulation J. 75(2011) 2755-2756.

12. Luk, A.J. and Simkin, P.A. Epidemiology of hyperuricemia and gout. Am. J. Managed Care 11 (2005) S435-S442.

13. Roddy, E. and Doherty, M. Epidemiology of gout. Arthritis Res. Ther. 12 (2010) 223.

14. Kuo, C.F., Grainge, M.J., Zhang, W. and Doherty, M. Global epidemiology of gout: prevalence, incidence and risk factors. Nature Rev. Rheumatol. 11 (2015) 649-662.

15. Zhu, Y., Pandya, B.J. and Choi, H.K. Prevalence of gout and hyperuricemia in the US general population: the National Health and Nutrition Examination Survey 2007-2008. Arthritis Rheumatol. 63 (2011) 3136-3141.

16. O'Sullivan, J.B. Gout in a New England town. A prevalence study in Sudbury, Massachusetts. Ann. Rheumatic Dis. 31 (1972) 166-169.

17. Kuo, C.F., Grainge, M.J., Mallen, C., Zhang, W. and Doherty, M. Rising burden of gout in the UK but continuing suboptimal management: a nationwide population study. Ann. Rheumatic Dis. 74 (2014) 661-667.

18. Ting, K., Gill, T.K., Keen, H., Tucker, G.R. and Hill, C.L. Prevalence and associations of gout and hyperuricaemia: results from an Australian population-based study. Intern. Med.J. 46(2016) 566-573.

19. Klemp, P., Stansfield, S.A., Castle, B. and Robertson, M.C. Gout is on the increase in New Zealand. Ann. Rheumatic Dis. 56 (1997) 22-26.

20. Guo, M., Cheng, Z., Li, C., Li, S., Li, M., Wang, M., Xu, J., Tang, Y., Wang, Y., Qiu, W. and Liu, X. Polymorphism of rs7688672 and rs10033237 in cGKII/PRKG2 and gout susceptibility of Han population in northern China. Gene 562 (2015) 50-54.

21. Ames, B.N., Cathcart, R., Schwiers, E. and Hochstein, P. Uric acid provides an antioxidant defence in humans against oxidant and radical. Proc. Natl Acad. Sci. USA 78 (1981) 6858-6862.

22. Keizman, D., Ish-Shalom, M., Berliner, S., Maimon, N., Vered, Y., Artamonov, I., Tsehori, J., Nefussy, B. and Drory, V.E. Low uric acid levels in serum of patients with ALS: Further evidence for oxidative stress? J. Neurol. Sci. 285 (2009) 95-99.

23. Johnson, R.J., Gaucher, E.A., Sautin, Y.Y., Henderson, G.N., Angerhofer, A.J. and Benner, S.A. The planetary biology of ascorbate and uric acid and their relationship with the epidemic of obesity and cardiovascular disease. Med. Hypotheses 71 (2008) 22-31.

24. Choi, H.K., Mount, D.B., Reginato, A.M., American College of Physicians and American Physiological Society. Pathogenesis of gout. Ann. Intern. Med. 143 (2005) 499-516.

25. Martinon, F. andGlimcher, L.H. Gout: new insights into an old disease. J. Clin. Invest. 116 (2006) 2073-2075.
26. Akahoshi, T., Namai, R., Murakami, Y., Watanabe, M., Matsui, T., Nishimura, A., Kitasato, H., Kameya, T. and Kondo, H. Rapid induction of peroxisome proliferatoractivated receptor gamma expression in human monocytes by monosodium urate monohydrate crystals. Arthritis Rheumatol. 48 (2003) 231-239.

27. Schumacher, H.R. Jr. Crystal-induced arthritis: an overview. Am. J. Med. 100 (1996) 46S-52S.

28. Seegmiller, J.E., Howell, R.R. and Malawista, S.E. The inflammatory reaction to sodium urate. JAMA 180 (1962) 469-475.

29. Pascual, E. and Jovani, V. A quantitative study of the phagocytosis of urate crystals in the synovial fluid of asymptomatic joints of patients with gout. $\mathrm{Br} . \mathrm{J}$. Rheumatol. 34 (1995) 724-726.

30. Yagnik, D.R., Hillyer, P., Marshall, D., Smythe, C.D., Krausz, T., Haskard, D.O. and Landis, R.C. Noninflammatory phagocytosis of monosodium urate monohydrate crystals by mouse macrophages: implications for the control of joint inflammation in gout. Arthritis Rheumatol. 43 (2000) 1779-1789.

31. Muniraj, N., Stamp, L.K., Badiei, A., Hegde, A., Cameron, V. and Bhatia, M. Hydrogen sulfide acts as a proinflammatory mediator in rheumatic disease. Int. J. Rheum. Dis. 20 (2017) 182-189.

32. Fox, B., Schantz, J.T., Haigh, R., Wood, M.E., Moore, P.K., Viner, N., Spencer, J.P., Winyard, P.G. and Whiteman, M. Inducible hydrogen sulfide synthesis in chondrocytes and mesenchymal progenitor cells: is $\mathrm{H}_{2} \mathrm{~S}$ a novel cytoprotective mediator in the inflamed joint? J. Cell Molec. Med. 16 (2012) 896-910.

33. Wallace, J.L. Hydrogen sulfide-releasing anti-inflammatory drugs. Trends Pharmacol. Sci. 28 (2007) 501-505.

34. Lowe, G.D., Lee, A.J., Rumley, A., Price, J.F. and Fowkes, F.G. Blood viscosity and risk of cardiovascular events: the Edinburgh Artery Study. Br. J. Haematol. 96 (1997) 168-173.

35. Zeng, C., Wei, J., Yang, T., Li, H., Xiao, W.-F., Luo, W., Gao, S.-G., Li, Y.-S., Xiong, Y.-L. and Lei, G.-H. Higher blood hematocrit predicts hyperuricemia: a prospective study of 62897 person-years of follow-up. Sci. Rep. 5 (2015) 13765.

36. Rosenson, R.S., Shott, S. and Tangney, C.C. Hypertriglyceridemia is associated with an elevated blood viscosity. Atherosclerosis 161 (2002) 433-439.

37. Irace, C., Carallo, C., Scavelli, F., De Franceschi, M.S., Esposito, T. and Gnasso, A. Blood viscosity in subjects with normoglycemia and prediabetes. Diabetes Care 37 (2014) 488-492.

38. Sloop, G.D. and Garber, D.W. The effects of low-density lipoprotein and high-density lipoprotein on blood viscosity correlate with their association with risk of atherosclerosis in humans. Clin. Sci. (Lond.) 92 (1997) 473-479.

39. Feng, C., Kedia, R.V., Hazzard, J.T., Hurley, J.K., Tollin, G. and Enemark, J.H. Effect of solution viscosity on intramolecular electron transfer in sulfite oxidase. Biochemistry 41 (2002) 5816-5821.

40. Feng, C., Wilson, H.L., Hurley, J.K., Hazzard, J.T., Tollin, G., Rajagopalan, K.V. and Enemark, J.H. Role of conserved tyrosine 343 in intramolecular electron transfer in human sulfite oxidase. J. Biol. Chem. 278 (2003) 2913-2920.

41. Swanson, N.L., Leu, A., Abrahamson, J. and Wallet, B. Genetically engineered crops, glyphosate and the 
deterioration of health in the United States of America. $J$. Org. Systems 9 (2014) 6-37.

42. Neel, B.A. and Sargis, R.M. The paradox of progress: environmental disruption of metabolism and the diabetes epidemic. Diabetes 60 (2011) 1838-1848.

43. Benbrook, C.M. Trends in glyphosate herbicide use in the United States and globally. Environ. Sci. Eur. 28 (2016) 3.

44. World Health Organization. IARC Monographs Volume 112: Evaluation of Five Organophosphate Insecticides and Herbicides (20 March 2015).

45. Mesnage, R., Renney, G., Séralini, G.E., Ward, M. and Antoniou, M.N. Multiomics reveal non-alcoholic fatty liver disease in rats following chronic exposure to an ultralow dose of Roundup ${ }^{\circledR}$ herbicide. Sci. Rep. 7 (2017) 39328.

46. de Souza, J.S., Letro Kizys, M.M., da Conceição, T.M., Glebocki, G., Romano, R.M., Ortiga-Carvalho, T.M., Giannocco, G., Guerreiro da Silva, I.D.C., Dias da Silva, M.R., Romano, M.A. and Chiamolera, M.I. Perinatal exposure to glyphosate-based herbicide alters the thyrotrophic axis and causes thyroid hormone homeostasis imbalance in male rats. Toxicology 377 (2017) 25-37.

47. Beecham, J.E. and Seneff, S. Is there a link between autism and glyphosate-formulated herbicides? J. Autism 3 (2016) 1.

48. Samsel, A. and Seneff, S. Glyphosate, pathways to modern diseases V: Aminos acid analogue of glycine in diverse proteins. J. Biol. Phys. Chem. 16 (2016) 9-46.

49. Seneff, S., Morley, W., Hadden, M.J. and Michener, M.C. Does glyphosate acting as a glycine analogue contribute to ALS? J. Bioinformatics Proteomics Rev. 2 (2016) 1-21.

50. Samsel, A. and Seneff, S. Glyphosate pathways to modern diseases VI: prions, amyloidoses and autoimmune neurological diseases. J. Biol. Phys. Chem. 17 (2017) 8-32.

51. Xu, J., Li, G., Wang, Z., Si, L., He, S., Cai, J., Huang, J. and Donovan, M.D. The role of L-type amino acid transporters in the uptake of glyphosate across mammalian epithelial tissues. Chemosphere 145 (2016) 487-494.

52. Yanagida, O., Kanai, Y., Chairoungdua, A., Kim, D.K., Segawa, H., Nii, T., Cha, S.H., Matsuo, H., Fukushima, J., Fukasawa, Y., Tani, Y., Taketani, Y., Uchino, H., Kim, J.Y., Inatomi, J., Okayasu, I., Miyamoto, K., Takeda, E., Goya, T. and Endou, H. Human L-type amino acid transporter 1 (LAT1): characterization of function and expression in tumor cell lines. Biochim. Biophys. Acta 1514 (2001) 291-302.

53. Ridley, W.P. and Mirly, K. The metabolism of glyphosate in Sprague Dawley rats. Part I. Excretion and tissue distribution of glyphosate and its metabolites following intravenous and oral administration. (Unpublished study MSL-7215 conducted by the Monsanto Environmental Health Laboratory and submitted to the EPA July 1988) MRID\#407671-01. 1988.

54. Samsel, A. and Seneff, S. Glyphosate, pathways to modern diseases IV: cancer and related pathologies. J. Biol. Phys. Chem. 15(2015) 121-159.

55. Samsel, A. and Seneff, S. Glyphosate's suppression of cytochrome P450 enzymes and amino acid biosynthesis by the gut microbiome: Pathways to modern diseases. Entropy 15(2013) 1416-1463.

56. Roddy, E. Revisiting the pathogenesis of podagra: why does gout target the foot? J. Foot Ankle Res. 4 (2011) 13.

57. Wilcox, W.R. and Khalaf, A.A. Nucleation of monosodium urate crystals. Ann. Rheumatic Dis. 34 (1975) 332-339.
58. Swanson, N.L., Hoy, J. and Seneff, S. Evidence that glyphosate is a causative agent in chronic sub-clinical metabolic acidosis and mitochondrial dysfunction. Int. J. Human Nutrition Functional Med. 4 (2016) 32-52.

59. Guo, Z., Zhang, J., Wang, Z., Ang, K.Y., Huang, S., Hou, Q., Su, X., Qiao, J., Zheng, Y., Wang, L., Koh, E., Danliang, H., $\mathrm{Xu}, \mathrm{J}$., Lee, Y.K. and Zhang, H. Intestinal microbiota distinguish gout patients from healthy humans. Sci. Rep. 6(2016) 20602.

60. Wei, B., Dalwadi, H., Gordon, L.K., Landers, C., Bruckner, D., Targan, S.R. and Braun, J. Molecular cloning of a Bacteroides caccae TonB-linked outer membrane protein identified by an inflammatory bowel disease marker antibody. Infect. Immun. 69 (2001) 6044-6054.

61. Matsuo, H., Nakayam, A. and Shinoiya, N. ABCG2 dysfunction causes hyperuricemia due to both renal urate underexcretion and renal urate overload. Sci. Rep. 4 (2014) 3375.

62. Polgar, O., Ozvegy-Laczka, C., Robey, R.W., Morisaki, K., Okada, M., Tamaki, A., Koblos, G., Elkind, N.B., Ward, Y., Dean, M., Sarkadi, B. and Bates, S.E. Mutational studies of G553 in TM5 of ABCG2: a residue potentially involved in dimerization. Biochemistry 45 (2006) 5251-5260.

63. Costantini, A.V. The fungal etiology of gout and hyperuricemia: the antifungal mode of action of colchicine. Biomed. Rev. 1 (1992) 47-52.

64. Nguyen, L.N., Lopes, L.C., Cordero, R.J. and Nosanchuk, J.D. Sodium butyrate inhibits pathogenic yeast growth and enhances the functions of macrophages. $J$. Antimicrob. Chemother. 66 (2011) 2573-2580.

65. Hutyra, F. and Marek, J. Special Pathology and Therapeutics of the Diseases of Domestic Animals. Vol III. Chicago: Alexander Eger (1926).

66. Pegram, R.A. and Wyatt, R.D. Avian gout caused by oosporein, a mycotoxin produced by Chaetomium trilaterale. Poultry Sci. 60 (1981) 2429-2440.

67. Mannig, R.O. and Wyatt, R.D. Comparative toxicity of Chaetomium contaiminated corn and various forms of oosporein in broiler chicks. Poultry Sci. 63 (1984) 251-259.

68. Kubena, L.F., Phillips, T.D., Creger, C.R., Witzel, D.A. and Heidelbaugh, N.D. Toxicity of Ochratoxin A and Tannic acid to growing chicks. Poultry Sci. 62 (1983) 1786-1792.

69. Yoshitomi, H., Sakaguchi, N., Kobayashi, K., Brown, G.D., Tagami, T., Sakihama, T., Hirota, K., Tanaka, S., Nomura, T., Miki, I., Gordon, S., Akira, S., Nakamura, T. and Sakaguchi, S. A role for fungal beta-glucans and their receptor Dectin-1 in the induction of autoimmune arthritis in genetically susceptible mice. J. Exp. Med. 201 (2005) 949-960.

70. Gibson, T., Rodgers, A.V., Simmonds, H.A and Toseland, P. Beer drinking and its effect on uric acid. Br. J. Rheumatol. 23 (1984) 203-209.

71. Nip, W.K., Chang, F.C., Chu, F.S. and Prentice, N. Fate of ochratoxin A in brewing. Appl. Microbiol. 30 (1975) 1048-1049.

72. Akbari, P., Braber, S., Varasteh, S., Alizadeh, A., Garssen, J. and Fink Gremmels, J. The intestinal barrier as an emerging target in the toxicological assessment of mycotoxins. Arch. Toxicol. 91 (2017) 1007-1029.

73. Kavanaugh, N.L., Zhang, A.Q., Nobile, C.J., Johnson, A.D. and Ribbecka, K. Mucins suppress virulence traits of Candida albicans. mBio 5 (2014) e01911-e01914. 
74. Finnie, I.A., Dwarakanath,A.D., Taylor, B.A. and Rhodes, J.M. Colonic mucin synthesis is increased by sodium butyrate. Gut 36 (1995) 93-99.

75. Tropcheva, R., Nikolova, D., Evstatieva, Y. and Danova, S. Antifungal activity and identification of Lactobacilli, isolated from traditional dairy product "katak." Anaerobe 28 (2014) 78-84.

76. Amdekar, S., Singh, V., Singh, R., Sharma, P., Keshav, P. and Kumar, A. Lactobacillus casei reduces the inflammatory joint damage associated with collagen-induced arthritis (CIA) by reducing the pro-inflammatory cytokines: Lactobacillus casei: COX-2 inhibitor. J. Clin. Immunol. 31 (2011) 147-154.

77. Archibald, F. Manganese: its acquisition by and function in the lactic acid bacteria. Crit. Rev. Microbiol. 13 (1986) 63-109.

78. Weinberg, E.D. The Lactobacillus anomaly: Total iron abstinence. Perspectives Biol. Med. 40 (1997) 4.

79. Samsel, A. and Seneff, S. Glyphosate, pathways to modern diseases III: Manganese neurological diseases, and associated pathologies. Surgical Neurol. Intl 6 (2015) 45.

80. Ott, S.J., Khbacher, T., Musfeldt, M., Rosenstiel, P., Hellmig, S., Rehman, A., Drews, O., Weichert, W., Timmis, K.N. and Schreiber, S. Fungi and inflammatory bowel diseases: Alterations of composition and diversity. Scand. J. Gastroenterol. 43 (2008) 831-841.

81. Pfaller, M.A. and Diekema, D.J. Epidemiology of invasive Candidiasis: a persistent public health problem. Clin. Microbiol. Rev. 20 (2007) 133-163.

82. Martin, G.S., Mannino, D.M., Eaton, S. and Moss, M. The epidemiology of sepsis in the United States from 1979 through 2000. N. Engl. J. Med. 348 (2003) 1546-1554.

83. Galvano, F., Ritieni, A., Piva, G. and Pietri,A. Mycotoxins in the human food chain. In: The Mycotoxin Blue Book (ed. D.E. Diaz), pp. 187-224. Nottingham: University Press (2005).

84. Azab, R.M., Tawakkol, W.M., Hamad, A.-R.M., AbouElmagd, M.K., El-Agrab, H.M. and Refai, M.K. Detection and estimation of aflatoxin B1 in feeds and its biodegradation by bacteria and fungi. Egyptian J. Natural Toxins 2 (2005) 39-56.

85. Barberis, C.L., Carranza, C.S., Chiacchiera, S.M. and Magnoli, C.E. Influence of herbicide glyphosate on growth and aflatoxin B1 production by Aspergillus section Flavi strains isolated from soil on in vitro assay. $J$. Environ. Sci. Health B 48 (2013) 1070-1079.

86. Eman,A., Sadik, M.W.,Abdel-Megeed,A.,Areej Suliman,A.-M. and Sholkamy, E.N. Biodegradation of glyphosate by fungal strains isolated from herbicides polluted-soils in Riyadh area. Intl J. Current Microbiol. Appl. Sci. 2 (2013) 359-381.

87. Bourgeosis, C.H., Shank, R.C., Grossman, R.A., Johnson, D.O., Wooding, W.L. and Chandavimol, P. Acute aflatoxin Bl toxicity in the macaque and its similarity to Reye's syndrome. Lab. Invest. 24 (1971) 206-216.

88. Li, M., Müller, T.A., Fraser, B.A. and Hausinger, R.P. Characterization of active site variants of xanthine hydroxylase from Aspergillus nidulans. Arch. Biochem. Biophys. 470 (2008) 44-53.

89. Hamad, H.O., Alma, M., Ismael, H.M. and Göçeri, A. The effect of some sugars on the growth of Aspergillus niger.
KSUJ. Nat. Sci. 17 (2014) 7-11.

90. Choi, H.K. and Curhan, G. Soft drinks, fructose consumption, and the risk of gout in men: prospective cohort study. $B M J$ 336 (2008) 309-312.

91. Batt, C., Phipps-Green, A.J., Black, M.A., Cadzow, M., Merriman, M.E., Topless, R., Gow, P., Harrison, A., Highton, J., Jones, P., Stamp, L., Dalbeth, N. and Merriman, T.R. Sugarsweetened beverage consumption: a risk factor for prevalent gout with SLC2A9 genotype-specific effects on serum urate and risk of gout. Ann. Rheumatic Dis. 73 (2014) 2101-2106.

92. Shea, P.J. and Tupy, D.R. Reversal of cation-induced reduction in glyphosate activity with EDTA. Weed Sci. 32 (1984) 802-806.

93. Ijssennagger, N., van der Meer, R. and van Mil, S.W.C. Sulfide as a mucus barrier-breaker in inflammatory bowel disease? Trends Molec. Med. 22 (2016) 190-199.

94. Gibson, G.R., Cummings, J.H. and Macfarlane, G.T. Growth and activities of sulfate-reducing bacteria in gut contents of healthy-subjects and patients with ulcerative-colitis. FEMS Microbiol. Ecol. 86 (1991) 103-111.

95. Levine, J., Ellis, C.J., Furne, J.K., Springfield, J. and Levitt, M.D. Fecal hydrogen sulfide production in ulcerative colitis. Am. J. Gastroenterol. 93 (1998) 83-87.

96. Lu, W., Li, L., Chen, M., Zhou, Z., Zhang, W., Ping, S., Yan, Y., Wang, J. and Lin, M. Genome-wide transcriptional responses of Escherichia coli to glyphosate, a potent inhibitor of the shikimate pathway enzyme 5enolpyruvylshikimate-3-phosphate synthase. Molec. BioSyst. 9 (2013) 522-530. Also: Supplementary Table S2. Functional description of genes downregulated in response to glyphosate shock.

97. Wang, M., Jia, Y., Xu, Z. and Xia, Z. Impairment of sulfite reductase decreases oxidative stress tolerance in Arabidopsis thaliana. Frontiers Plant Sci. 7 (2016) 1843.

98. Zaidi, A., Khan, M.S. and Rizvi, P.Q. Effect of herbicides on growth, nodulation and nitrogen content of greengram. Agronomy Sustain. Dev. 25 (2005) 497-504.

99. Nafziger, E.D., Widholm, J.M., Steinrcken, H.C. and Killmer, J.L. Selection and characterization of a carrot cell line tolerant to glyphosate. Plant Physiol. 76 (1984) 571-574.

100. Murphy, M.J. and Siegel, L.M. Siroheme and sirohydrochlorin: The basis for a new type of porphyrin-related prosthetic group common to both assimilatory and dissimilatory sulfite reductases. J. Biol. Chem. 248 (1973) 6911-6919.

101. Marquet, P., Duncan, S.H., Chassard, C., BernalierDonadille, A. and Flint, H.J. Lactate has the potential to promote hydrogen sulphide formation in the human colon. FEMS Microbiol. Lett. 299 (2009) 128-134.

102. Seneff, S., Davidson, R.M., Lauritzen, A., Samsel, A. and Wainwright, G. A novel hypothesis for atherosclerosis as a cholesterol sulfate deficiency syndrome. Theor. Biol. Med. Modelling 12 (2015) 9.

103. Linares,P.M., Chaparro, M., Algaba, A., Romn, M., Moreno Arza, I., Abad Santos, F., Ochoa, D., Guerra, I., Bermejo, F. and Gisbert, J.P. Effect of chondroitin sulphate on pro-inflammatory mediators and disease activity in patients with Inflammatory Bowel Disease. Digestion 92 (2015) 203-210.

104. Segarra, S., Martnez-Subiela, S., Cerdà-Cuéllar, M., 
Martnez-Puig, D., Muñoz-Prieto, A., Rodríguez-Franco, F., Rodríguez-Bertos, A., Allenspach, K., Velasco, A. and Cerón, L. Oral chondroitin sulfate and prebiotics for the treatment of canine Inflammatory Bowel Disease: A randomized, controlled clinical trial. BMC Vet. Res. 12 (2016) 49 .

105. Greif, D.M., Sacks, D.B. and Michel, T. Calmodulin phosphorylation and modulation of endothelial nitric oxide synthase catalysis. Proc. Natl Acad. Sci. USA 101 (2004) 1165-1170.

106.Landmesser,U., Dikalov, S., Price, S.R., McCann, L., Fukai, T., Holland, S.M., Mitch, W.E. and Harrison, D.G. Oxidation of tetrahydrobiopterin leads to uncoupling of endothelial cell nitric oxide synthase in hypertension. $J$. Clin. Invest. 111 (2003) 1201-1209.

107. Seneff, S., Lauritzen, A., Davidson, R. and Lentz-Marino, L. Is endothelial nitric oxide synthase a moonlighting protein whose day job is cholesteroll sulfate synthesis? Implications for cholesterol transport, diabetes and cardiovascular disease. Entropy 14 (2012) 2492-2530.

108. Fernandes, H.P., Cesar, C.L. and de Lourdes Barjas-Castro, M. Electrical properties of the red blood cell membrane and immunohematological investigation. Rev. Bras. Hematol. Hemoter. 33 (2011) 297-301.

109. Nikolaides,M.G., Bausch, A.R., Hsu, M.F., Dinsmore, A.D., Brenner, M.P., Gay, C. and Weitz, D.A. Electric-fieldinduced capillary attraction between like-charged particles at liquid interfaces. Nature 420 (2002) 299-301.

110. Cacace, M.G., Landau, E.M. and Ramsden, J.J. The Hofmeister series: salt and solvent effects on interfacial phenomena. Q. Rev. Biophys. 30 (1997) 241-277.

111. Collins, K.D. Ions from the Hofmeister series and osmolytes: effects on proteins in solution and in the crystallization process. Methods 34 (2004) 300-311.

112. Jansson,E.A., Huang, L., Malkey, R., Govoni, M., Nihlén, C., Olsson, A., Stensdotter, M., Petersson, J., Holm, L., Weitzberg, E. and Lundberg, J.O. A mammalian functional nitrate reductase that regulates nitrite and nitric oxide homeostasis. Nature Chem. Biol. 4 (2008) 411-417.

113. Zhang, Z., Naughton, D., Winyard, P.G., Benjamin, N., Blake, D.R. and Symons, M.C. Generation of nitric oxide by a nitrite reductase activity of xanthine oxidase: a potential pathway for nitric oxide formation in the absence of nitric oxide synthase activity. Biochem. Biophys. Res. Commun. 249 (1998) 767-772.

114. Stevens,C.R., Benboubetra, M., Harrison, R., Sahinoglu, T., Smith, E.C. and Blake, D.R. Localisation of xanthine oxidase to synovial endothelium. Ann. Rheumatic Dis. 50 (1991) 760-762.

115. Wilson, H.L, Wilkinson, S.R. and Rajagopalan, K.V. The G473D mutation impairs dimerization and catalysis in human sulfite oxidase. Biochemistry 45 (2006) 2149-2160.

116. Cakmak, I., Yazici, A., Tutus, Y. and Ozturk, L. Glyphosate reduced seed and leaf concentrations of calcium, manganese, magnesium, and iron in non-glyphosate resistant soybean. Eur. J. Agronomy 31 (2009) 114-119.

117. Carmi-Nawi, N., Malinger, G., Mandel, H., Ichida, K., Lerman-Sagie, T. and Lev, D. Prenatal brain disruption in molybdenum cofactor deficiency. J. Child Neurol. 26 (2011) 460-464.

118. Sass, J.O., Gunduz, A., Araujo Rodrigues Funayama, C.,
Korkmaz, B., Dantas Pinto, K.G., Tuysuz, B., Yanasse Dos Santos, L., Taskiran, E., de Ftima Turcato, M., Lam, C.W., Reiss, J., Walter, M., Yalcinkaya, C. and Camelo, J.S. Jr. Functional deficiencies of sulfite oxidase: Differential diagnoses in neonates presenting with intractable seizures and cystic encephalomalacia. Brain Dev. 32 (2010) 544-549.

119. Topcu, M., Coskun, T., Haliloglu, G. and Saatci, I. Molybdenum cofactor deficiency: report of three cases presenting as hypoxic-ischemic encephalopathy. J. Child Neurol. 16 (2001) 264-270.

120. Ford, B., Bateman, L.A., Gutierrez-Palominos, L., Park, R. and Nomura, D.K. Mapping proteome-wide targets of glyphosate in mice. Cell Chem. Biol. 24 (2017) 133-140.

121. Stafford, C.T., Niedermeier, W., Holley, H.L. and Pigman, W. Studies on the concentration and intrinsic viscosity of hyaluronic acid in synovial fluids of patients with rheumatic diseases. Ann. Rheumatic Dis. 23 (1964) 152-157.

122. Velayutham, M., Hemann, C.F., Cardounel, A.J. and Zweier, J.L. Sulfite oxidase activity of cytochrome c: Role of hydrogen peroxide. Biochem. Biophys. Rep. 5 (2016) 96-104.

123. Slot, O. Homocysteine, a marker of cardiovascular disease risk, is markedly elevated in patients with gout. Ann. Rheumatic Dis. 72 (2013) 457.

124. McCully, K.S. Chemical pathology of homocysteine. V. thioretinamide, thioretinaco, and cystathionine synthase function in degenerative diseases. Ann. Clin. Lab. Sci. 41 (2011) 300-313.

125. Aitken, R.J., Flanagan, H.M., Connaughton, H., Whiting, S., Hedges, A. and Baker, M.A. Involvement of homocysteine, homocysteine thiolactone, and paraoxonase type 1 (PON-1) in the etiology of defective human sperm function. Andrology 4 (2016) 345-360.

126. Jiang, Y.J., Kim, P., Elias, P.M. and Feingold, K.R. LXR and PPAR activators stimulate cholesterol sulfotransferase type 2 isoform $1 \mathrm{~b}$ in human keratinocytes. J. Lipid Res. 46 (2005) 2657-2666.

127. Ferretti, G., Bacchetti, T., Masciangelo, S. and Bicchiega, V. Effect of homocysteinylation on high density lipoprotein physico-chemical properties. Chem. Phys. Lipids 163 (2010) 228-235.

128. Yilmaz, N. Relationship between paraoxonase and homocysteine: crossroads of oxidative diseases. Arch. Med. Sci. 8 (2012) 138-153.

129. Lombardi, R., Pisano, G. and Fargion, S. Role of serum uric acid and ferritin in the development and progression of NAFLD. Intl J. Molec. Sci. 17 (2016) 548.

130.Pisano, G., Lombardi, R. and Fracanzani A.L. Vascular damage in patients with nonalcoholic fatty liver disease: Possible role of iron and ferritin. Int. J. Mol. Sci. 17 (2016) 675.

131. Williams, C.D., Stengel, J., Asike, M.I., Torres, D.M., Shaw, J., Contreras, M., Landt, C.L. and Harrison, S.A. Prevalence of nonalcoholic fatty liver disease and nonalcoholic steatohepatitis among a largely middle-aged population utilizing ultrasound and liver biopsy: A prospective study. Gastroenterology 140 (2011) 124-131.

132. Lonardo, A., Ballestri, S., Marchesini, G., Angulo, P. and Loria, P. Nonalcoholic fatty liver disease: A precursor of the metabolic syndrome. Digestive Liver Dis. 47 (2015) $181-190$ 
133. Schreinemachers, D.M. and Ghio, A.J. Effects of environmental pollutants on cellular iron homeostasis and ultimate links to human disease. Environ. Health Insights 10 (2016) 35-43.

134. El-Shenawy, N.S. Oxidative stress responses of rats exposed to Roundup and its active ingredient glyphosate. Environ. Toxicol. Pharmacol. 28 (2009) 379-385.

135. Fargion, S., Mattioli, M., Fracanzani, A.L., Sampietro, M., Tavazzi, D., Fociani, P., Taioli, E., Valenti, L. and Fiorelli, G. Hyperferritinemia, iron overload, and multiple metabolic alterations identify patients at risk for nonalcoholic steatohepatitis. Am. J. Gastroenterol. 96 (2001) 2448-2455.

136. Mainous, A.G. 3rd, Knoll, M.E., Everett, C.J., Matheson, E.M., Hulihan, M.M. and Grant, A.M. Uric acid as a potential cue to screen for iron overload. J. Am. Board Family Med. 24 (2011) 415-421.

137. Ghio, A.J., Ford, E.S., Kennedy, T.P. and Hoidal, J.R. The association between serum ferritin and uric acid in humans. Free Radical Res. 39 (2005) 337-342.

138.Facchini, FS. Near-iron deficiency-induced remission of gouty arthritis. Rheumatology (Oxford) 42 (2003) 1550-1555.

139. Ghio, A.J., Kennedy, T.P., Rao, G., Cooke, C.L., Miller, M.J. and Hoidal, J.R.Complexation of iron cation by sodium urate crystals and gouty inflammation. Arch. Biochem. Biophys. 313 (1994) 215-221.

140. d'Eshougues, J.R., Leonardelli, J., Delcambre, B., Zylberberg, G. and Hubaud, P. Importance of the presence of iron in the subintimal synovial tissue in rheumatoid disease. [Article in French] Rev. Rhumatisme Maladies Osteo-Articulaires 39 (1972) 573-580.

141. Dominici, S., Pieri, L., Comporti, M. and Pompella, A. Possible role of membrane gamma-glutamyltransferase activity in the facilitation of transferrin-dependent and independent iron uptake by cancer cells. Cancer Cell Intl $3(2003) 7$.

142. Iglesias-Osma, C., Gonzalez-Villaron, L., San Miguel, J.F., Caballero, M.D., Vazquez, L. and de Castro, S. Iron metabolism and fungal infections in patients with haematological malignancies. J. Clin. Pathol. 48 (1995) 223-225.

143. Kontoyiannis, D.P., Chamilos, G., Lewis, R.E., Giralt, S., Cortes, J., Raad, I.I., Manning, J.T. and Han, X. Increased bone marrow iron stores is an independent risk factor for invasive aspergillosis in patients with high-risk hematologic malignancies and recipients of allogeneic hematopoietic stem cell transplantation. Cancer 110 (2007) 1303-1306.

144. Spacek, J., Jilek, P., Buchta, V., Forstl, M., Hronek, M. and Holeckova, M. The serum levels of calcium, magnesium, iron and zinc in patients with recurrent vulvovaginal candidosis during attack, remission and in healthy controls. Mycoses 48 (2005) 391-395.

145. Farrajota, K., Cheng, S., Martel-Pelletier, J., Afif, H., Pelletier, J.-P., Li, X., Ranger, P. and Fahmi, H. Inhibition of interleukin- $1 \beta$-induced cyclooxygenase 2 expression in human synovial fibroblasts by 15 -Deoxy- $\Delta 12,14$ prostaglandin J2 through a histone deacetylase-independent mechanism. Arthritis Rheumatol. 52 (2005) 94-104.

146. Koenig, G. and Seneff, S. Gamma-glutamyltransferase: A predictive biomarker of cellular antioxidant inadequacy and disease risk. Disease Markers 2015 (2015) 818570.
147. Lee, D.H. and Jacobs, D.R. Is serum gammaglutamyltransferase an exposure marker of xenobiotics? Empirical evidence with polycylic aromatic hydrocarbon. Clin. Chem. Lab. Med. 47 (2009) 860-862.

148. Jasper, R., Locatelli, G.O., Pilati, C. and Locatelli, C. Evaluation of biochemical, hematological and oxidative parameters in mice exposed to the herbicide glyphosateRoundup ${ }^{\circledR}$. Interdiscip. Toxicol. 5 (2012) 133-140.

149. Sedda, V., De Chiara, B., Parolini, M., Caruso, R., Campolo, J., Cighetti, G., De Maria, R., Sachero, A., Donato, L. and Parodi, O. Plasma glutathione levels are independently associated with gamma-glutamyltransferase activity in subjects with cardiovascular risk factors. Free Radical Res. 42 (2008) 135-141.

150.Nie, P., Li, D., Hu, L., Jin, S., Yu, Y., Cai, Z., Shao, Q., Shen, J., Yi, J., Xiao, H., Shen, L. and He, B. Atorvastatin improves plaque stability in ApoE-knockout mice by regulating chemokines and chemokine receptors. PLoS ONE 9(2014) e97009.

151. Celik, O., Cakmak, H.A., Satilmis, S., Gungor, B., Akin, F., Ozturk, D., Yalcin, A.A., Ayca, B., Erturk, M., Atasoy, M.M. and Uslu, N. The relationship between gamma-glutamyl transferase levels and coronary plaque burdens and plaque structures in young adults with coronary atherosclerosis. Clin. Cardiol. 37 (2014) 552-557.

152. Rambabu, K., Ansari, A.A., Shaafie, I.A., Chelvam, A.P. and Ziu, M.M. Gamma-glutamyl transpeptidase in synovial fluid, serum, and urine of patients with rheumatoid arthritis. Biochem. Med. Metabolic Biol. 43 (1990) 183-92.

153. Moriwaki, S., Into, T., Suzuki, K., Miyauchi, M., Takata, T., Shibayama, K. and Niida, S. $\gamma$-Glutamyltranspeptidase is an endogenous activator of Toll-like receptor 4-mediated osteoclastogenesis. Sci. Rep. 6 (2016) 35930.

154. Qing, Y.F., Zhang, Q.B., Zhou, J.G. and Jiang, L. Changes in toll-like receptor (TLR)4-NFkB-IL1 signaling in male gout patients might be involved in the pathogenesis of primary gouty arthritis. Rheumatol. Int. 34 (2014) 213-20.

155. Jaronczyk, K., Bui, L., Soong, J.M., McLaughlin, B.E., Marks, G.S., Brien, J.F. and Nakatsu, K. The source of heme for vascular heme oxygenase II: de novo heme biosynthesis in rat aorta. Can. J. Physiol. Pharmacol. 82 (2004) 218-24.

156. Hildebrandt, T.M. and Grieshaber, M.K. Three enzymatic activities catalyze the oxidation of sulfide to thiosulfate in mammalian and invertebrate mitochondria. FEBS J. 275 (2008) 3352-3361.

157. Kitchen, L.M., Witt, W.W. and Rieck, C.E. Inhibition of $\gamma-$ aminolevulinic acid synthesis by glyphosate. Weed Sci. 29 (1981) 571-577.

158. Hellsten, Y., Tullson, P.C., Richter, E.A. and Bangsbo, J. Oxidation of urate in human skeletal muscle during exercise. Free Radical Biol. Med. 22 (1997) 169-174.

159. Hellsten, Y., Sjödin, B., Richter, E.A. and Bangsbo, J. Urate uptake and lowered ATP levels in human muscle after high-intensity intermittent exercise. Am. J. Physiol. Endocrinol. Metabolism 274 (1998) E600-E606.

160. Kurahashi, H., Watanabe, M., Sugimoto, M., Ariyoshi, Y., Mahmood, S., Araki, M., Ishii, K., Nasu, Y., Nagai, A. and Kumon, H. Testosterone replacement elevates the serum uric acid levels in patients with female to male gender identity disorder. Endocr. J. 60 (2013) 1321-1327. 
161. Wallimann, T., Tokarska-Schlattner, M. and Schlattner, U. The creatine kinase system and pleiotropic effects of creatine. Amino Acids 40 (2011) 1271-1296.

162. Ferns, G.A.A., Lanham, J., Stocks, J., Ritchie, C., Katz, J. and Galton, D.J. The measurement of high density lipoprotein subtractions in patients with primary gout using a simple precipitation method. Ann. Clin. Biochem. 22 (1985) 526-532.

163. Robinson, D.S. and French, J.E. Heparin, the clearing factor lipase, and fat transport. Pharmacol. Rev. 12 (1960) 241-263.

164. Tsutsumi, Z., Yamamoto, T., Moriwaki, Y., Takahashi, S. and Hada, T. Decreased activities of lipoprotein lipase and hepatic triglyceride lipase in patients with gout. Metabolism 50 (2001) 952-954.

165. Kumar Yadav, S.K., Dubey, A.K., Yadav, S., Bisht, D., Darmwa, N.S. and Yadav, D. Amino acid sequences based phylogenetic and motif assessment of lipases from different organisms. Online J. Bioinformatics 13 (2012) 400-417.

166. Terkeltaub, R., Curtiss, L.K., Tenner, A.J. and Ginsberg, MH. Lipoproteins containing apoprotein $\mathrm{B}$ are a major regulator of neutrophil responses to monosodium urate crystals. J. Clin. Invest. 73 (1984) 1719-1730.

167. Hirose, N., Blankenship, D.T., Krivanek, M.A., Jackson, R.L. and Cardin, A.D. Isolation and characterization of four heparin-binding cyanogen bromide peptides of human plasma apolipoprotein B. Biochemistry 26 (1987) 5505-5512.

168. Egeberg, M., Kjeken, R., Kolset, S.O., Berg, T. and Prydz, K. Internalization and stepwise degradation of heparan sulfate proteoglycans in rat hepatocytes. Biochim. Biophys. Acta 1541 (2001) 135-149.

169. Gray, D.A. and Woulfe, J. Lipofuscin and aging: a matter of toxic waste. Sci. Aging Knowledge Environ. 2005 (2005) re1.

170. Guha, S., Liu, J., Baltazar, G., Laties, A.M. and Mitchell, C.H. Rescue of compromised lysosomes enhances degradation of photoreceptor outer segments and reduces lipofuscinlike autofluorescence in retinal pigmented epithelial cells. Adv. Exp. Med. Biol. 801 (2014) 105-111.

171. Vieira, A.T., Galvão, I., Macia, L.M., Sernaglia, É.ME., Vinolo, M.A., Garcia, C.C., Tavares, L.P., Amaral, F.A., Sousa, L.P., Martins, F.S., Mackay, C.R. and Teixeira, M.M. Dietary fiber and the short-chain fatty acid acetate promote resolution of neutrophilic inflammation in a model of gout in mice. J. Leukocyte Biol. 101 (2017) 275-284.

172. Brisson, L., Bański, P., Sboarina, M., Dethier, C., Danhier, P., Fontenille, M.J., Van He, V.F., Vazeille, T., Tardy, M., Falces, J., Bouzin, C., Porporato, P.E., Frédérick, R., Michiels, C., Copetti, T. and Sonveaux, P. Lactate dehydrogenase B controls lysosome activity and autophagy in cancer. Cancer Cell 30 (2016) 418-431.

173. Kurz, T., Terman, A., Gustafsson, B. and Brunk, U.T. Lysosomes in iron metabolism, ageing and apoptosis. Histochem. Cell Biol. 129 (2008) 389-406.

174. Kayashima, T. and Katayama, T. Oxalic acid is available as a natural antioxidant in some systems. Biochim. Biophys. Acta 1573 (2002) 1-3.

175.Haghparast, S., Kashiri, H., Shabanpour, B. and Pahlavani, M.H. Antioxidant properties of sodium acetate, sodium citrate and sodium lactate on lipid oxidation in rainbow trout (Onchorhynchus mykiss) sticks during refrigerated storage. Iranian J. Fisheries Sci. 9 (2010) 73-86.

176. Ross, M.A., Long, W.F. and Williamson, F.B. Inhibition by heparin of $\mathrm{Fe}$ (II)-catalysed free-radical peroxidation of linolenic acid. Biochem. J. 286 (1992) 717-720.

177. Ebara, T., Conde, K., Kako, Y., Liu, Y., Xu, Y., Ramakrishnan, R., Goldberg, I.J. and Shachter, N.S. Delayed catabolism of apoB-48 lipoproteins due to decreased heparan sulfate proteoglycan production in diabetic mice. J. Clin. Invest. 105 (2000) 1807-1818.

178. Rasheed, H., Hsu, A., Dalbeth, N., Stamp, L.K., McCormick, S. and Merriman, T.R. The relationship of apolipoprotein B and very low density lipoprotein triglyceride with hyperuricemia and gout. Arthritis Res. Ther. 16 (2014) 495.

179. Terkeltaub, R.A., Dyer, C.A., Martin, J. and Curtiss, L.K. Apolipoprotein (apo) E inhibits the capacity of monosodium urate crystals to stimulate neutrophils. Characterization of intraarticular apo $\mathrm{E}$ and demonstration of apo E binding to urate crystals in vivo. J. Clin. Invest. 87 (1991) 20-26.

180. Paka, L., Kako, Y., Obunike, J.C. and Pillarisetti, S. Apolipoprotein E containing high density lipoprotein stimulates endothelial production of heparan sulfate rich in biologically active heparin-like domains: a potential mechanism for the anti-atherogenic actions of vascular apolipoprotein E. J. Biol. Chem. 274 (1999) 4816-4823.

181. Kawahito, Y., Kondo, M., Tsubouchi, Y., Hashiramoto, A., Bishop-Bailey, D., Inoue, K.-I., Kohno, M., Yamada, R., Hla, T. and Sano, H. 15-deoxy- $\delta 12,14-P G J 2$ induces synoviocyte apoptosis and suppresses adjuvant-induced arthritis in rats. J. Clin. Invest. 106 (2000) 189-197.

182. Empson, V.G., McQueen, F.M. and Dalbeth, N. The natural killer cell: a further innate mediator of gouty inflammation? Immunol. Cell Biol. 88 (2010) 24-31.

183. Dahlén, S.-E. and Kumlin, M. Monitoring mast cell activation by prostaglandin D2 in vivo. Thorax 59 (2004) 453-455.

184. Oschatz, C., Maas, C., Lecher, B., Jansen, T., Bjrkqvist, J., Tradler, T., Sedlmeier, R., Burfeind, P., Cichon, S., Hammerschmidt, S., Mller-Esterl, W., Wuillemin, W.A., Nilsson, G. and Renn, T. Mast cells increase vascular permeability by heparin-initiated bradykinin formation in vivo. Immunity 34 (2011) 258-268.

185. Ren, S., Kim, J.K., Kakiyama, G., Rodriguez-Agudo, D., Pandak, W.M., Min, H.-K. and Ning, Y. Identification of novel regulatory cholesterol metabolite, 5-cholesten, 3,25diol, disulfate. PLOS ONE 9 (2014) e103621.

186. Grebe, A. and Latz, E. Cholesterol crystals and inflammation. Current Rheumatol. Rep. 15 (2013) 313.

187. Fam, A.G. Cholesterol crystals in gouty bursitis. J. Rheumatol. 28(2001) 1928-1929.

188. Fam, A.G. Subcutaneous cholesterol crystal deposition and tophus formation. Arthritis Rheumatol. 32 (1989) 1190-1191.

189. Ying, Z., Kherada, N., Farrar, B., Kampfrath, R., Chung, Y., Simonetti, O., Deiuliis, J., Desikan, R., Khan, B., Villamena, S., Sun, Q., Parthasarathy, S. and Rajagopalan, S. Lipoic acid effects on established atherosclerosis. Life Sci. 86 (2010) 95-102.

190. Orantes-Navarro, C.M., Herrera-Valdés, R., AlmaguerLópez, M., López Marín, L., Vela-Parada, X.F., Hernandez- 
Cuchillas, M. and Barba, L.M.. Toward a comprehensive hypothesis of chronic interstitial nephritis in agricultural communities. Adv. Chron. Kidney Dis. 24 (2017) 101-106

191. Kupferman, J., Amador, J.J., Lynch, K.E., Laws, R.L., LópezPilarte, D., Ramírez-Rubio, O., Kaufman, J.S., Lau, J.L., Weiner, D.E., Robles, N.V., Verma, K.P., Scammell, M.K., McClean, M.D., Brooks, D.R. and Friedman, D.J. Characterization of Mesoamerican nephropathy in a kidney failure hotspot in Nicaragua. Am. J. Kidney Dis. 68 (2016) 716-725.

192. Jayasumana, C., Gunatilake, S. and Senanayake, P. Glyphosate, hard water and nephrotoxic metals: are they the culprits behind the epidemic of chronic kidney disease of unknown etiology in Sri Lanka? Int. J. Environ. Res. Public Health 11 (2014) 2125-2147.

193. Roncal-Jimenez, C., Garca-Trabanino, R., Barregard, L., Lanaspa, M.A., Wesseling, C., Harra, T., Aragón, A., Grases, F., Jarquin, E.R., González, M.A., Weiss, I., Glaser, J., Sánchez-Lozada, L.G. and Johnson, R.J. Heat stress nephropathy from exercise-induced uric acid crystalluria: a perspective on mesoamerican nephropathy. Am. J. Kidney Dis. 67 (2016) 20-30.

194. Tasian, G.E., Ross, M.E., Song, L., Sas, D.J., Keren, R., Denburg, M.R., Chu, D.I., Copelovitch, L., Saigal, C.S. and Furth, S.L. Annual incidence of nephrolithiasis among children and adults in South Carolina from 1997 to 2012. Clin. J. Am. Soc. Nephrol. 11 (2016) 488-496.

195. Coe, F.L. Treated and untreated recurrent calcium nephrolithiasis in patients with idiopathic hypercalciuria, hyperuricosuria, or no metabolic disorder. Ann. Intern. Med. 87 (1977) 404- 410.

196. Coe, F.L. Uric acid and calcium oxalate nephrolithiasis. Kidney Int. 24 (1983) 392-403.

197. Grover, P.K., Ryall, R.L. and Marshall, V.R. Calcium oxalate crystallization in urine: role of urate and glycosaminoglycans. Kidney Int. 41 (1992) 149-154.

198. Coe, F.L., Lawton, R.L., Goldstein, R.B. and Tembe, V. Sodium urate accelerates precipitation of calcium oxalate in vitro. Proc. Soc. Exp. Biol. Med. 149 (1975) 926-929.

199. Oppici, E., Roncador, A., Montioli, R., Bianconi, S. and Cellini, B. Gly161 is a highly conserved residue whose mutation to Arg, Cys or Ser is associated with PH1. Biochim. Biophys. Acta 1832 (2013) 2277-2288.

200. Cellini, B., Montioli, R., Paiardini, A., Lorenzetto, A., Maset, F., Bellini, T., Oppici, E. and Voltattorni, C.B. Molecular defects of the glycine 41 variants of alanine glyoxylate aminotransferase associated with primary hyperoxaluria type I. Proc. Natl Acad. Sci. USA 107 (2010) 2896-2901. 